\title{
The evolution of sexually dimorphic cuticular hydrocarbons in blowflies (Diptera: Calliphoridae)
}

\author{
Running title: Cuticular hydrocarbon evolution in blowflies
}

\begin{abstract}
NATHAN J. BUTTERWORTH ${ }^{1 *}$ (nb187@uowmail.edu.au)
\end{abstract}
ORCID ID: 0000-0002-5679-2700

\author{
JAMES F. WALLMAN ${ }^{1,2}$ (James.Wallman@uts.edu.au) \\ FALKO P. DRIJFHOUT ${ }^{3}$ (f.drijfhout@keele.ac.uk) \\ NIKOLAS P. JOHNSTON¹ (npj304@uowmail.edu.au) \\ PAUL A. KELLER ${ }^{4}$ (keller@uow.edu.au) \\ PHILLIP G. BYRNE¹ (pbyrne@uow.edu.au)
}

${ }^{1}$ Centre for Sustainable Ecosystem Solutions, School of Earth, Atmospheric and Life Sciences,

University of Wollongong, Wollongong, NSW, Australia

${ }^{2}$ School of Life Sciences, University of Technology Sydney, Ultimo NSW, Australia

${ }^{3}$ School of Chemical and Physical Sciences, Keele University, Keele, UK

${ }^{4}$ School of Chemistry and Molecular Bioscience, Molecular Horizons, University of Wollongong and Illawarra Health and Medical Research Institute, Wollongong, Australia.

$$
\begin{aligned}
& \text { *Corresponding author: nb187@uowmail.edu.au } \\
& \text { Ph:+61451 } 102548
\end{aligned}
$$

This article has been accepted for publication and undergone full peer review but has not been through the copyediting, typesetting, pagination and proofreading process, which may lead to differences between this version and the Version of Record. Please cite this article as doi: $\underline{10.1111 / J E B .13685}$

This article is protected by copyright. All rights reserved 
MR. NATHAN JOHN BUTTERWORTH (Orcid ID : 0000-0002-5679-2700)

PROFESSOR JAMES F WALLMAN (Orcid ID : 0000-0003-2504-6075)

Article type : Research Papers

\section{The evolution of sexually dimorphic cuticular hydrocarbons in blowflies (Diptera: Calliphoridae)}

Abstract Cuticular hydrocarbons (CHCs) are organic compounds found on the cuticles of all insects which can act as close-contact pheromones, while also providing a hydrophobic barrier to water loss. Given their widespread importance in sexual behaviour and survival, CHCs have likely contributed heavily to the adaptation and speciation of insects. Despite this, the patterns and mechanisms of their diversification have been studied in very few taxa. Here, we perform the first study of CHC diversification in blowflies, focussing on wild populations of the ecologically diverse genus Chrysomya. We convert CHC profiles into qualitative and quantitative traits and assess their inter- and intra-specific variation across 10 species. We also construct a global phylogeny of Chrysomya, onto which CHCs were mapped to explore the patterns of their diversification. For the first time, we demonstrate that blowflies express an exceptional diversity of $\mathrm{CHCs}$, which have diversified in a non-phylogenetic and punctuated manner, are species-specific, and sexually dimorphic. It is likely that both ecological and sexual selection have shaped these patterns of CHC diversification, and our study now provides a comprehensive framework for testing such hypotheses.

Keywords - Cuticular hydrocarbons, sexual selection, diversification, blowflies, Diptera, Calliphoridae 


\section{Introduction}

There are now numerous examples of phenotypic traits that experience divergent ecological selection while also contributing to non-random mating (Servedio et al. 2011). These so called "magic" or "dual" traits occur frequently in nature and have the potential to drive speciation (Chung and Carroll 2015). Despite this, our understanding of how these traits evolve, and the extent to which they have facilitated speciation, remains poorly understood. One such example are cuticular hydrocarbons (CHCs) - mixtures of long straight-chained, olefinic, and methyl-branched hydrocarbons found within the waxy cuticle of all insects. $\mathrm{CHCs}$ are essential to the survival of terrestrial insects, forming a hydrophobic layer that can adapt to environmental changes to prevent cuticular water loss (Chung and Carroll 2015; Stinziano et al. 2015; Sprenger et al. 2018). CHCs have also been adapted as close-range pheromones, facilitating species recognition and sexual attraction in a wide range of insects (Ferveur 2005; Curtis et al. 2013; Hughes et al. 2015; Ingleby 2015). Thus, CHCs provide a classic example of a dual trait, as they are a salient target for selection on: 1) their waterproofing capabilities and 2) their communication function in inter- and intra-specific interactions (Chung and Carroll 2015).

Given their widespread importance in survival and reproduction, $\mathrm{CHCs}$ have likely contributed to the divergent evolution and speciation of insects (Smadja and Butlin 2009; Chung and Carroll 2015; Menzel et al. 2017a). However, past studies have mostly been limited to ants (Martin et al. 2008; van Wilgenburg et al. 2011; Kather and Martin 2015; Menzel et al. 2017a; Menzel et al. 2017b), wasps and bees (Buellesbach et al. 2013; Van Oystaeyen et al. 2014; Kather and Martin 2015; Buellesbach et al. 2018), and fruit flies 
(Bartelt et al. 1986; Jallon and David 1987; Alves 2010; Oliveira et al. 2011), with few studies on groups of species outside of these model taxa (Phasmatodea: Schwander et al. 2013, Orthoptera: Mullen et al. 2007, Diptera: Symonds et al. 2009, Coleoptera: Niogret et al. 2019). Nevertheless, from this work, it is clear that the patterns of CHC diversification vary greatly between different insect groups. For example, in some taxa $\mathrm{CHC}$ diversification between related species occurs gradually, typically resulting in greater similarity in substances and concentrations between closely related species compared to distant relatives. This is most evident in certain flies (Bartelt et al. 1985; Symonds and Wertheim 2005) and ants (Martin et al. 2008) and may occur when selective pressure on CHCs is relaxed, perhaps when CHC function is substituted by different compounds or physiological mechanisms (van Wilgenburg et al. 2011). Conversely however, CHC diversification can also occur saltationally, where rapid changes between closely related species result in drastic differences in their CHC substances and concentrations, as appears to be the case in some ants (Menzel et al. 2017b; Kather et al. 2015), wasps (Buellesbach et al. 2013; Kather et al. 2015), flies (Symonds et al. 2009), and stick insects (Schwander et al. 2013). In these cases, rapid diversification of $\mathrm{CHC}$ profiles may result from divergent ecological adaptation, as well as from sexual selection favouring rapid saltational changes in sender and receiver communication channels.

However, given the overwhelming variability of insect $\mathrm{CHCs}$, the apparent mode of $\mathrm{CHC}$ diversification can be easily confounded by the experimental approach. Specifically, approaches taken by previous studies have been highly variable, making it difficult to compare findings within and between taxa. These experimental differences can be primarily attributed to the choice of data type, and a lack of consideration to intra-specific variation. Regarding data type, if $\mathrm{CHC}$ composition is considered quantitatively (substance concentration) versus qualitatively (presence or absence of a substance or substance classes), then conclusions about the mode of CHC diversification can be vastly different. This is well demonstrated by studies of CHC diversification in Crematogaster ants, where qualitatively, CHCs appear to evolve under a gradual mode of evolution (van Wilgenburg et al. 2011), while quantitatively, CHCs appear to evolve rapidly and in a non-phylogenetic manner (Menzel et al. 2017a). Thus, it is best that studies consider both qualitative and quantitative variation in $\mathrm{CHCs}$.

Regarding intra-specific variation, CHC expression can differ substantially between wild and lab-reared populations (Toolson et al. 1990; Mullen et al. 2007; Dapporto et al. 2013), 
between sexes (Buellesbach et al. 2013; Stinziano et al. 2015), and between different life history stages (Caputo et al. 2005; Roux et al. 2008; Arienti et al. 2010; Kuo et al. 2012; Butterworth et al. in press). Despite this, many comparative studies have not addressed these factors, instead working primarily with lab populations, and only considering a single sex or period of development. If we are to elucidate the broader patterns of CHC diversification, and more deeply understand their contribution to insect diversification, then a more comprehensive approach will be needed. Specifically, we propose that much will be gained from exploring $\mathrm{CHC}$ diversification in a wider range of non-model taxa, assessing both quantitative and qualitative variation, performing studies in wild populations, and carefully considering differences in expression between sexes and different life stages.

The blowflies (Diptera: Calliphoridae) provide a particularly useful model system for the comprehensive study of $\mathrm{CHC}$ evolution. There are approximately 1,200 described species, many of which have well documented life histories and have been placed phylogenetically (Kutty et al. 2010; Marinho et al. 2012; Nelson et al. 2012; Kutty et al. 2019). They are also ecologically diverse (Ferrar 1987), and carrion-breeding species can be easily captured in the wild in numbers required for comparative studies. There is also increasing evidence that CHCs are involved in blowfly survival and reproduction (Goodrich 1970; Trabalon et al. 1992; Stoffolano 1997; Butterworth et al. 2019), and there is substantial species-level variation in CHC composition (Roux et al. 2008; Pechal et al. 2014; Barbosa et al. 2017), which is suggestive of divergent evolution. However, no attempt has been made to consider these findings in a phylogenetic context; so how the evolutionary diversification of CHCs in blowflies relates to their unique ecologies, and compares with other insects, remains unclear. Nevertheless, if CHCs have contributed to the speciation of blowflies, we would expect to see evidence of saltational evolution between species, and sexually dimorphic profile composition within species.

Within the Australasian region, the blowfly genus Chrysomya is particularly diverse and represents an untapped model system for evolutionary research (Wells and Kurahashi 1996). There are nine representative species in Australia, all of which can be found along the eastern coast of the country, occupying a diverse range of habitats, from temperate rainforests in the north to dry schlerophyll forests in the colder southern regions (Kitching and Voeten 1977). They also exhibit varied modes of reproduction (Norris 1959) and show substantial variation in their mating systems (Butterworth et al. 2019). Given their diverse distributions and ecologies, they provide an ideal opportunity to investigate the evolutionary diversification of 
CHCs. As such, in the present study we undertake the first comprehensive analysis of CHCs in blowflies by assessing variation between species and sexes in a phylogenetic context using wild populations of Chrysomya. The specific aims of our study were to: 1) identify the CHC substances expressed across all Australian Chrysomya, 2) assess inter-specific variation in CHCs, 3) assess intra-specific variation in CHCs, 4) generate a new global phylogeny for the Chrysomya and 5) assess how CHCs have diversified in the context of this phylogeny. By addressing these aims, we expect to provide new insights into $\mathrm{CHC}$ diversification in flies, and, more broadly, provide a platform for hypotheses concerning the role these complex dual traits have played in the speciation and evolution of blowflies.

\section{METHODS AND MATERIALS}

Insect collection. Nine species of Australian Chrysomya were collected from sites along the east coast of Australia ranging from Wollongong, NSW to Brisbane, QLD between December 2016 and April 2018 (Table 1). In addition, a single laboratory strain of Australian Lucilia cuprina was used as an outgroup. Wild flies were manually netted over carrion bait, and for each species 10-20 adults of each sex were collected, for a total of 321 individual flies.

Table 1. Site data for all collected Chrysomya and Lucilia species.

\begin{tabular}{|c|c|c|c|c|}
\hline Species & Abbreviation & Location & Latitude & Longitude \\
\hline \multirow[t]{6}{*}{ Ch. rufifacies } & Ruf & Anstead, QLD & -27.53 & 152.85 \\
\hline & & Kholo, QLD & -27.49 & 152.75 \\
\hline & & Mount Coot-Tha, QLD & -27.28 & 152.58 \\
\hline & & Wollongong, NSW & -34.43 & 150.89 \\
\hline & & Tuggerah, NSW & -33.29 & 151.42 \\
\hline & & Yarramundi, NSW & -33.67 & 150.68 \\
\hline \multirow[t]{5}{*}{ Ch. incisuralis } & Inc & Anstead, QLD & -27.53 & 152.85 \\
\hline & & Advancetown, QLD & -28.07 & 153.26 \\
\hline & & Cowarra, NSW & -31.53 & 152.79 \\
\hline & & Yarramundi, NSW & -33.67 & 150.68 \\
\hline & & Wollongong, NSW & -34.43 & 150.89 \\
\hline \multirow[t]{4}{*}{ Ch. nigripes } & $\mathrm{Nig}$ & Calamia, NSW & -29.85 & 153.06 \\
\hline & & Ferodale, NSW & -32.71 & 151.84 \\
\hline & & Yarramundi, NSW & -33.67 & 150.68 \\
\hline & & Cedar Creek, QLD & -27.33 & 152.80 \\
\hline Ch. flavifrons & $\mathrm{Fla}$ & Mount Coot-Tha, QLD & -27.28 & 152.58 \\
\hline
\end{tabular}

This article is protected by copyright. All rights reserved 


\begin{tabular}{|c|c|c|c|c|}
\hline & & Cedar Creek, QLD & -27.33 & 152.80 \\
\hline \multirow[t]{5}{*}{ Ch. varipes } & Var & Advancetown, QLD & -28.07 & 153.26 \\
\hline & & Mount Coot-Tha, QLD & -27.28 & 152.58 \\
\hline & & Cedar Creek, QLD & -27.33 & 152.80 \\
\hline & & Valery, NSW & -30.30 & 152.97 \\
\hline & & Wollongong, NSW & -34.43 & 150.89 \\
\hline \multirow[t]{5}{*}{ Ch. megacephala } & Meg & Anstead, QLD & -27.53 & 152.85 \\
\hline & & Mount Coot-Tha, QLD & -27.28 & 152.58 \\
\hline & & Valery, NSW & -30.30 & 152.97 \\
\hline & & Tuggerah, NSW & -33.29 & 151.42 \\
\hline & & Wollongong, NSW & -34.43 & 150.89 \\
\hline \multirow[t]{4}{*}{ Ch. saffranea } & Saf & Anstead, QLD & -27.53 & 152.85 \\
\hline & & Kholo, QLD & -27.49 & 152.75 \\
\hline & & Mount Coot-Tha, QLD & -27.28 & 152.58 \\
\hline & & Valery, NSW & -30.30 & 152.97 \\
\hline \multirow[t]{4}{*}{ Ch. semimetallica } & Sem & Anstead, QLD & -27.53 & 152.85 \\
\hline & & Mount Coot-Tha, QLD & -27.28 & 152.58 \\
\hline & & Cedar Creek, QLD & -27.33 & 152.80 \\
\hline & & Valery, NSW & -30.30 & 152.97 \\
\hline \multirow[t]{4}{*}{ Ch. latifrons } & Lat & Cowarra, NSW & -31.53 & 152.79 \\
\hline & & Valery, NSW & -30.30 & 152.97 \\
\hline & & Tuggerah, NSW & -33.29 & 151.42 \\
\hline & & Wollongong, NSW & -34.43 & 150.89 \\
\hline L. cuprina* & Cup & ERC, Wollongong, NSW & NA & NA \\
\hline
\end{tabular}

*L. cuprina were from a lab population maintained at the University of Wollongong's Ecological Research Centre (ERC).

Flies were euthanised at $-20^{\circ} \mathrm{C}$ within $8 \mathrm{~h}$ of collection, and any particulate matter adhering to flies was removed. To confirm morphological species identifications, the DNA barcode region of CO1 was amplified, and sequenced following the methods of Nelson et al. 2007. CO1 was extracted, amplified, and sequenced from one individual per species. Sequences were then compared to the GenBank database via BLASTn and identified based on sequence similarity.

Chemical analysis. Cuticular hydrocarbons were extracted from 10-20 individual males and females of each species within $2 \mathrm{~h}$ of euthanasia. Flies were immersed in $400 \mu \mathrm{L} n$-hexane in a $1 \mathrm{~mL}$ glass vial for $5 \mathrm{~min}$, gently vortexed using an S.E.M. vortex mixer (Adelab Scientific, Australia), then removed from the solution. Washed flies were inspected following extraction to ensure that no cuticular damage had occurred, which may have caused internal fluids to leak. Samples were stored at $-40^{\circ} \mathrm{C}$ for up to 30 days. Prior to analysis, samples were evaporated with nitrogen and reconstituted in $20 \mu \mathrm{L}$ of hexane containing an internal standard (2 ppm pentadecane). A sample $(1 \mu \mathrm{L})$ of this $\mathrm{CHC}$ extract was then injected into a gas chromatography mass spectrometer (GC-MS; Agilent 7890 GC coupled with an Agilent 7000 
Triple-Quad MS and an Agilent 7693 Autosampler) fitted with an Rxi-5ms column (20 m x $0.18 \mathrm{~mm}$ ID; d.f. $=0.18 \mu \mathrm{m}$ ) and using helium as the carrier gas at a flow rate of $0.8 \mathrm{~mL} / \mathrm{min}$. The inlet temperature was set to $270^{\circ} \mathrm{C}$ and injection performed in splitless mode. The column was held isothermally at $50^{\circ} \mathrm{C}$ for $1 \mathrm{~min}$, then ramped at a rate of $40^{\circ} \mathrm{C} / \mathrm{min}$ to $180^{\circ} \mathrm{C}$, before ramping at $5^{\circ} \mathrm{C} / \mathrm{min}$ to $300^{\circ} \mathrm{C}$. The mass spectrometer was operated at $70 \mathrm{eV}$ with a source temperature of $280^{\circ} \mathrm{C}$ and scanning was performed from $\mathrm{m} / z, 40$ to 500 .

Pre-treatment of data. Peaks were selected between C21 and C40, and only those that occurred in at least 3 specimens were manually integrated using Masshunter qualitative analysis B06.00. Retention indices were calculated by comparing peak elution times to those of a C7-C40 alkane standard. Hydrocarbons were identified by analysis of their mass spectra, identification of diagnostic ions, and corroboration with published Kovats indices. There were some compounds in L. cuprina which we were unable to identify (peaks 58-62). We have taken a conservative approach to the analysis by assuming that these compounds are synonymous with those found in Chrysomya. However, on this assumption, we have likely underestimated the divergence of Lucilia CHCs from those in Chrysomya, and further analysis of Lucilia CHCs will likely reveal a greater number of compounds that are unique to this genus. Peak areas from all 10 species were aligned by their retention indices using $\mathrm{R}$ package GCalignR (Ottensmann et al. 2018) and manually inspected to assure conformance. Data were then converted to relative abundances by dividing the area of each peak by the total peak area, followed by the addition of a small constant $(0.01)$ to remove zeros. For quantitative comparisons, data were transformed by centered log ratio with the $\mathrm{R}$ package 'Hotelling' (Curran 2018) and auto scaled using the inbuilt R function (R Core Team 2019) following Hervé et al. (2018). For qualitative comparisons, raw data were instead converted to a binary matrix, where compound absence was represented by ' 0 ' and presence by ' 1 ', followed by transformation into a similarity matrix using the 'dist.binary' function (using Jaccard's similarity index, whereby double zeros are not considered as similarities) of the R package 'ade4' (Dray and Dufour 2007).

Statistical analysis. To test whether the quantitative differences of CHCs sufficiently discriminated species, while also accounting for the effect of sex, redundancy discriminant analysis (RDA) was performed on the entire transformed dataset using the $\mathrm{R}$ packages 'vegan' (Oksanen et al. 2019) and 'RVAideMemoire' (Hervé 2020). To validate the effect of species and sex on CHC variation, the total percentage of constrained variance explained by sex and species was estimated by a canonical $R^{2}$ called the 'bimultivariate redundancy 
statistic' (Miller and Farr 1971; Peres-Neto et al. 2006; Hervé et al. 2018). For our dataset, species, sex, and their interaction explained $46 \%$ of the total chemical variation, meaning that $54 \%$ of the variation could be due to noise, or any uncontrolled factors including diet, environment, or age. To test whether the constrained variance was explaining a significant proportion of the compositional data, a permutation $F$-test based on the canonical $R^{2}$ was performed (Legendre and Legendre 2012; Hervé et al. 2018). For our dataset, the test was declared significant (PERMANOVA; $\mathrm{F}_{19,301}=13.77, \mathrm{P}<0.001$ ), which implies that the chosen factors (species and sex) explained a significant proportion of the total quantitative chemical variation. As such, to test for the individual effects of the factors, a second permutation $F$-test was performed for species, sex, and the species $\times$ sex interaction. Then, pairwise comparisons (with corrections for multiple comparisons) were made using the function 'pairwise.factorfit' from 'RVAideMemoire' to specifically assess which species and sexes differed significantly from each other. Additionally, to test whether qualitative differences separated species, principal coordinate analysis (PCoA) was conducted on the similarity matrix (representing binary compositional differences between species) using the function 'dbrda' from 'RVAideMemoire' and then species- and sex-differences were assessed using the function 'pairwise.factorfit' as described above.

In order to visualize and compare these sex-specific differences within species, principal component analysis (PCA) was conducted on 10 reduced sets of data, each representing an individual species. Univariate analysis of variance (ANOVA) was performed on the extracted PCs for each of the 10 species. In order to determine which PCs represented the greatest proportion of the total variation, and should be analysed by ANOVA, we used the broken stick model and screeplot approaches (Jolliffe 2002; Quinn and Keough 2002). In addition, upon initial observation of the total ion chromatograms, we noticed substantial within-sex variation for male and female $C h$. varipes, male and female $C h$. flavifrons, and female $C h$. nigripes. These qualitatively distinct profiles showed intra-sexual differences in $\mathrm{CHC}$ expression (particularly in the chain lengths of expressed CHCs). These distinct profiles most likely correspond to age-specific differences, which has been confirmed for Ch. varipes (Butterworth et al. in press). Hereafter, these distinct $\mathrm{CHC}$ profiles will be referred to as 'types'. To consider the effect of type within species, we conducted pairwise comparisons on the previously extracted PCs using the function 'pairwise.factorfit' from 'RVAideMemoire' to test which types differed significantly within these species. All PCA and ANOVA analyses 
were performed using $\mathrm{R}$ base package ( $\mathrm{R}$ Core Team 2019), and the R packages 'Factoextra' (Kassambra and Mundt 2017), and 'ggFortify' (Tang et al. 2016).

Phylogenetic inference. To produce a global phylogenetic tree for the genus Chrysomya, previously published sequence data for $\mathrm{CO} 1, \mathrm{CO} 2, \mathrm{ND} 4$, and $\mathrm{CAD}$ were retrieved from GenBank (Nelson et al. 2007, Nelson et al. 2008, Nelson et al. 2012, Singh et al. 2011, Wallman et al. 2005 and Wells et al. 2001). The final data represented 27 Chrysomya species and four outgroup taxa (two Lucilia and two Calliphora; taxa list available: Supplementary Material 1: Table 1). Data were concatenated, and aligned in Geneious Prime version 2019.0.3 (https://www.geneious.com) using the MUSCLE algorithm (Edgar 2004; MUSCLE parameters: gap opening penalty $=-400$, gap extension penalty $=0$, Clustering Method $=$ UPGMB, Maximum diagonal length =24). Aligned data were analysed in PartitionFinder2 (Lanfear et al. 2016), which determines the best partitioning scheme and corresponding evolutionary model based upon which partition and model produced the highest Akaike information criterion (AICc) value. This optimum partitioning scheme (Supplementary Material 1: Table 1), was then used in all subsequent analyses. The final partitioned alignment was then submitted for both Maximum Likelihood (ML) and Bayesian (BA) analysis in the online CIPRES platform (Miller et al. 2010). ML analysis was performed in RAxML version 8.0 (Stamatakis 2014). Since RAxML only allows for a single evolutionary model to be applied to partitioned analyses, all partitions were analysed under the GTR+G model (1000 bootstrap iterations). BA analysis was performed in MrBayes version 3.2.6 utilising the BEAGLE library. Models of rate evolution were applied to each partition individually following the PartionFinder2 calculated 'best model' (Supplementary Material 1: Table 2). Four simultaneous Bayesian analyses were completed utilising four Markov Chain Monte Carlo $(\mathrm{MCMC})$ chains (three heated, one cold; temperature default $=0.1$; all priors at default settings) run for 20 million generations, sampling every 2000 generations (for a total of 40000 samples). A consensus tree was then prepared from the resultant trees with the first $25 \%$ of all trees discarded as burn-in. A final tree graphic summarising both analyses (ML and BA) was produced using FigTree version 1.4.3 (available from: http://tree.bio.ed.ac.uk/software/figtree/) and edited in Adobe Illustrator 2019 (available from: https://www.adobe.com/au/products/illustrator).

Evolutionary change in CHCs. To visually infer evolutionary change in CHC quantities, a second PCA was performed on the entire transformed dataset. The broken stick model and screeplot suggested that the first three PCs explained the greatest proportion of the total 
variation. As such, to visualize the evolution of $\mathrm{CHC}$ profiles, we traced the first three principal components onto a pruned phylogeny using parsimony reconstruction in the trace character history function of Mesquite V3.6 (Maddison and Maddison 2019). Both sexes were analysed together in the PCA, but male and female PCs were mapped separately. Additionally, because three species (Ch. varipes, Ch. flavifrons, and Ch. nigripes) expressed multiple qualitatively distinct profile types, we only mapped the PCs corresponding to the most common profile types, under the assumption that these represented the sexually mature profiles. For Ch. varipes, the sexually mature profile types were known to be male 'type 2' and female 'type 2' (Butterworth et al. in press). For the other species, the most common types (assumed to be sexually mature) were male 'type 2' and female 'type 2' for Ch. flavifrons and female 'type 2' for Ch. nigripes. We made this assumption on the basis that the response of adult blowflies to cues released from decaying carrion does not peak until approximately three days after adults emerge from the puparium (Ashworth and Wall 1995), and thus the majority of flies encountered around carrion tend to be older than three days and approaching sexual maturity. In support of this, we only caught three immature male and five immature female $C h$. varipes in the wild, compared to $>12$ mature adults of both sexes.

To assess which specific patterns of character change best described the diversification of hydrocarbon profiles among Chrysomya, we used the program CoMET (Continuouscharacter Model Evaluation and Testing) (Lee et al. 2006) within Mesquite V3.6 (Maddison and Maddison 2019). Specifically, we evaluated whether CHC proportions and CHC profiles (represented by PCs) have diverged gradually in line with our proposed phylogenetic tree, or rapidly and independently of our phylogenetic tree. The CoMET program achieves this by testing nine unique models of character change, which represent all combinations of three different phylogenetic models with three different rate models (in a 3 x 3 matrix). The phylogenetic models explain character change as pure-phylogenetic, non-phylogenetic, or punctuated. Whereas the rate models evaluate three different rates (distance, equal, and free) at which the character can change on each branch. Overall, CoMET estimates the fit of these nine models to our phylogenetic tree, from which Akaike Criterion (AIC) values are calculated to determine which model best characterizes the rate and mode of $\mathrm{CHC}$ diversification (Schwander et al. 2013). For detailed model explanations, model interpretations, and best-model conclusions, see Supplementary Material 1: Table 3.

\section{RESULTS}

This article is protected by copyright. All rights reserved 
Chemical analysis. Flies were collected along the east coast of Australia, with extractions resulting in 89 compounds among Chrysomya, and an additional three compounds unique to L. cuprina (peaks 47, 53 and 56) - for a total of 92 unique hydrocarbons (ranging from 21 to 36 carbon atoms in length) across the 10 species. For average peak proportions, retention times, and compound identifications refer to Supplementary Material 2, and for the entire raw dataset refer to Supplementary Material 3. Qualitatively, 40/92 CHCs (43\%) were found across all 10 species, and all $n$-alkanes, ranging from $\mathrm{C} 21$ to $\mathrm{C} 31$, were expressed by every species. Further to this, the proportions of substance classes were generally conserved among species, with monomethylalkanes, $n$-alkanes, and $n$-alkenes occurring in the greatest proportions (Figure 1). Conversely, species varied substantially in the total number of compounds they expressed, ranging from 62 unique $\mathrm{CHCs}$ in $C h$. varipes to 83 unique $\mathrm{CHCs}$ in Ch. flavifrons. Furthermore, there was considerable quantitative variation in the abundances of $\mathrm{CHC}$ substances (including the ubiquitous $n$-alkanes) between species, sexes, and types (Figure 1).

Inter-specific comparisons. To assess the extent of the inter-specific variation detected, while accounting for sex, both RDA and PCoA were performed to assess quantitative and qualitative differences respectively. The RDA revealed that species and sex explained a significant proportion of overall quantitative chemical variation across the 10 species (Figure 2). Of the constrained variance (the variance explained by species and sex), discriminant components $1-5$ collectively accounted for $76.28 \%$ of the variation, and a permutation $F$-test suggested that species (PERMANOVA; $\mathrm{F}_{9,301}=21.64, \mathrm{P}<0.001$ ), sex (PERMANOVA; $\left.\mathrm{F}_{1,301}=7.85, \mathrm{P}<0.001\right)$, and the species $\times$ sex interaction $\left(\right.$ PERMANOVA; $\mathrm{F}_{9,301}=6.42, \mathrm{P}<$ 0.001) each individually explained a significant proportion of this variation. Thus, to determine which species and which sexes differed significantly, pairwise comparisons were made, which revealed that almost all species separated significantly from their closest relatives (Pairwise comparison: $\mathrm{P}<0.05$ ) (For all pairwise comparisons see supplementary material 4: Table 1).

This article is protected by copyright. All rights reserved 


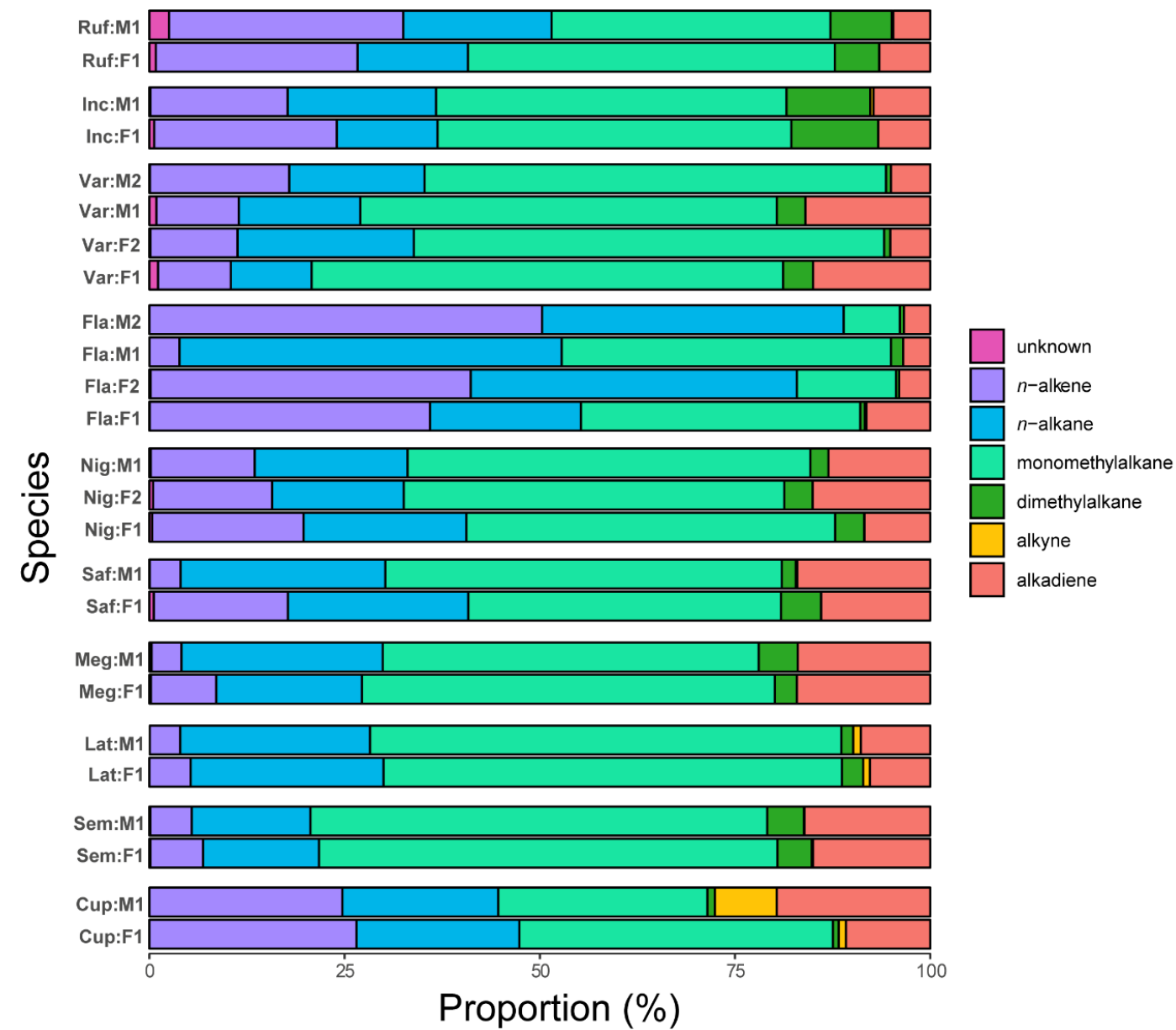

Figure 1. Average proportions of CHC substance classes found among Australian Chrysomya and Lucilia species. Ruf $=$ Ch. rufifacies, Inc $=$ Ch. incisuralis, Var $=C h$. varipes, $\mathrm{Fla}=C h$. flavifrons, Nig $=$ Ch. nigripes, Saf $=$ Ch. saffranea, Meg $=$ Ch. megacephala, Lat $=$ Ch. latifrons, Sem $=$ Ch. semimetallica, Cup $=$ L. cuprina . The vertical order of species follows the same vertical order as the phylogeny (Figure 4), with close relatives being positioned next to each other. Generated with ggplot2 (Wickham et al. 2019) in R (R Core Team 2019). Edited with Adobe Illustrator.

This was with two exceptions. Males of Ch. rufifacies were not distinct from Ch. incisuralis males (Pairwise comparison: $\mathrm{P}=0.35$ ) or females (Pairwise comparison: $\mathrm{P}=0.62$ ). Interestingly, however, Ch. rufifacies females were distinct from $C h$. incisuralis females (Pairwise comparison: $\mathrm{P}<0.01$ ). Further, Ch. saffranea females were not distinct from $C h$. megacephala males (Pairwise comparison: $\mathrm{P}=0.19$ ). Notably, several species that were distantly related shared quantitatively similar profile types (Pairwise comparison: $\mathrm{P}>0.05$ ) (Figure 2). Regarding qualitative differences between species, the results from pairwise comparisons of the PCoA closely matched those from the RDA, where all species separated significantly from their closest relatives, but several distantly related species overlapped substantially in their qualitative CHC composition (Supplementary Material 4: Table 2).

This article is protected by copyright. All rights reserved 
Intra-specific comparisons. To investigate and visualize sex- and type-specific differences within species, PCA, followed by univariate ANOVA (for sex differences) and pairwise comparisons (for type differences), were performed for reduced datasets which individually represented each species (Figure 3). Regarding between-sex differences, PCs 1-5 explained the greatest proportion of total variation in all species. As such, ANOVA was performed on extracted PCs 1-5 for each species; revealing significant differences in quantitative profile composition between the sexes (in at least one PC) for eight of 10 species (For PCA-ANOVA results, refer to Supplementary Material 4: Table 3). For all peak contributions to PCs 1-5 for each species, refer to Supplementary Material 4: Table 4. However, for Ch. varipes and $C h$. semimetallica, none of the five PCs significantly separated sex, suggesting that CHCs were not sexually dimorphic in these species (in support of the results from of the RDA analysis above). Notably, while RDA suggested that Ch. incisuralis, Ch. megacephala, and Ch. latifrons sexes were not statistically different, PCA-ANOVA revealed differences in at least one PC in three species, providing evidence that the CHCs contributing to those PCs may be sexually dimorphic to some degree. To see which peaks may be candidate pheromones based on differences in relative abundances between the sexes, refer to Supplementary Material 4: Table 5. For the three species that showed multiple profile types (Ch. varipes, Ch. flavifrons, and Ch. nigripes), pairwise comparisons revealed that type was statistically significant for each species (Table 2). Specifically, all male and female types were significantly different within Ch. flavifrons and Ch. nigripes. However, for Ch. varipes, comparisons between male type 1 and female type 1 , as well as male type 2 and female type 2, were not statistically significant, suggesting that there is substantial within-sex variation in CHC profiles corresponding to age, but reinforcing the notion that male and female $\mathrm{CHCs}$ are not substantially sexually dimorphic.

Table 2. Results of pairwise comparisons of PCA output for species that showed multiple CHC profile types, using the function 'pairwise.factorfit' from the 'RVAideMemoire' package of R. 'F1', 'F2', 'M1', 'M2' correspond to female type 1, female type 2, male type 1 and male type 2 respectively. A) Chrysomya varipes, B) Chrysomya nigripes and C) Chrysomya flavifrons. Numbers in bold represent significant results.

\begin{tabular}{rr|ccc}
\hline a) & Chrysomya varipes & F2 & F1 & M1 \\
& F1 & $\mathbf{0 . 0 0 3}$ & - & - \\
M2 & 0.102 & $\mathbf{0 . 0 0 3}$ & - \\
& M1 & $\mathbf{0 . 0 0 8}$ & 0.366 & $\mathbf{0 . 0 0 8}$ \\
\hline b) Chrysomya nigripes & F1 & F2 & \\
\hline F2 & $\mathbf{0 . 0 0 1}$ & - &
\end{tabular}

This article is protected by copyright. All rights reserved 


\begin{tabular}{rr|ccc} 
M1 & 0.001 & 0.001 & \\
\hline c) Chrysomya flavifrons & F1 & F2 & M1 \\
\hline F2 & 0.002 & 0.002 & 0.002 & - \\
M2 & 0.002 & 0.029 & 0.002
\end{tabular}
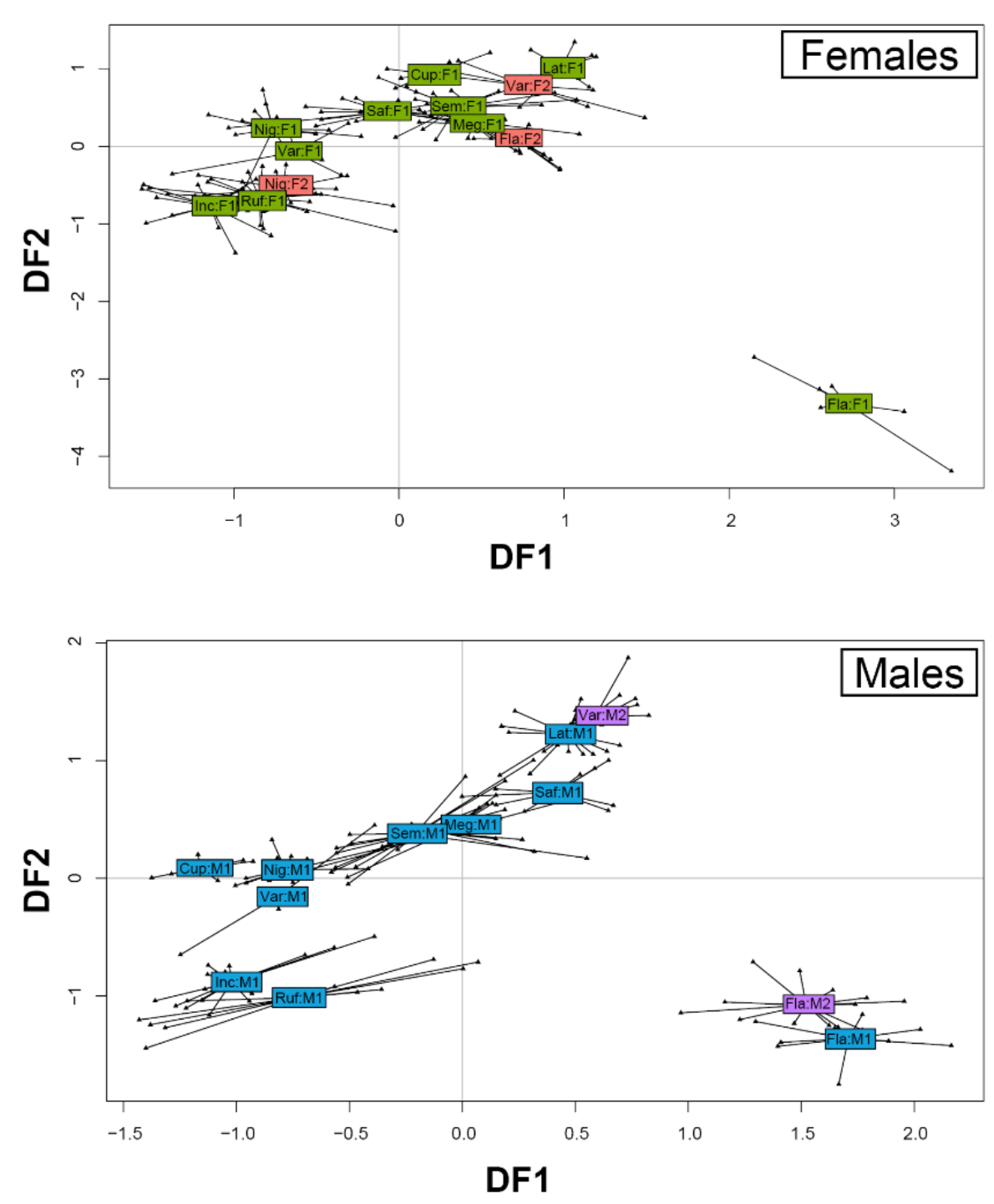

Figure 2. Interspecific variation of female and male Chrysomya CHC profiles. All species are separated by redundancy discriminant components (DF1 and DF2) from the RDA output. Axes show different scales. 
Generated using the 'MVA.plot' function of the package RVAideMemoire in R. Figures edited in adobe Illustrator.
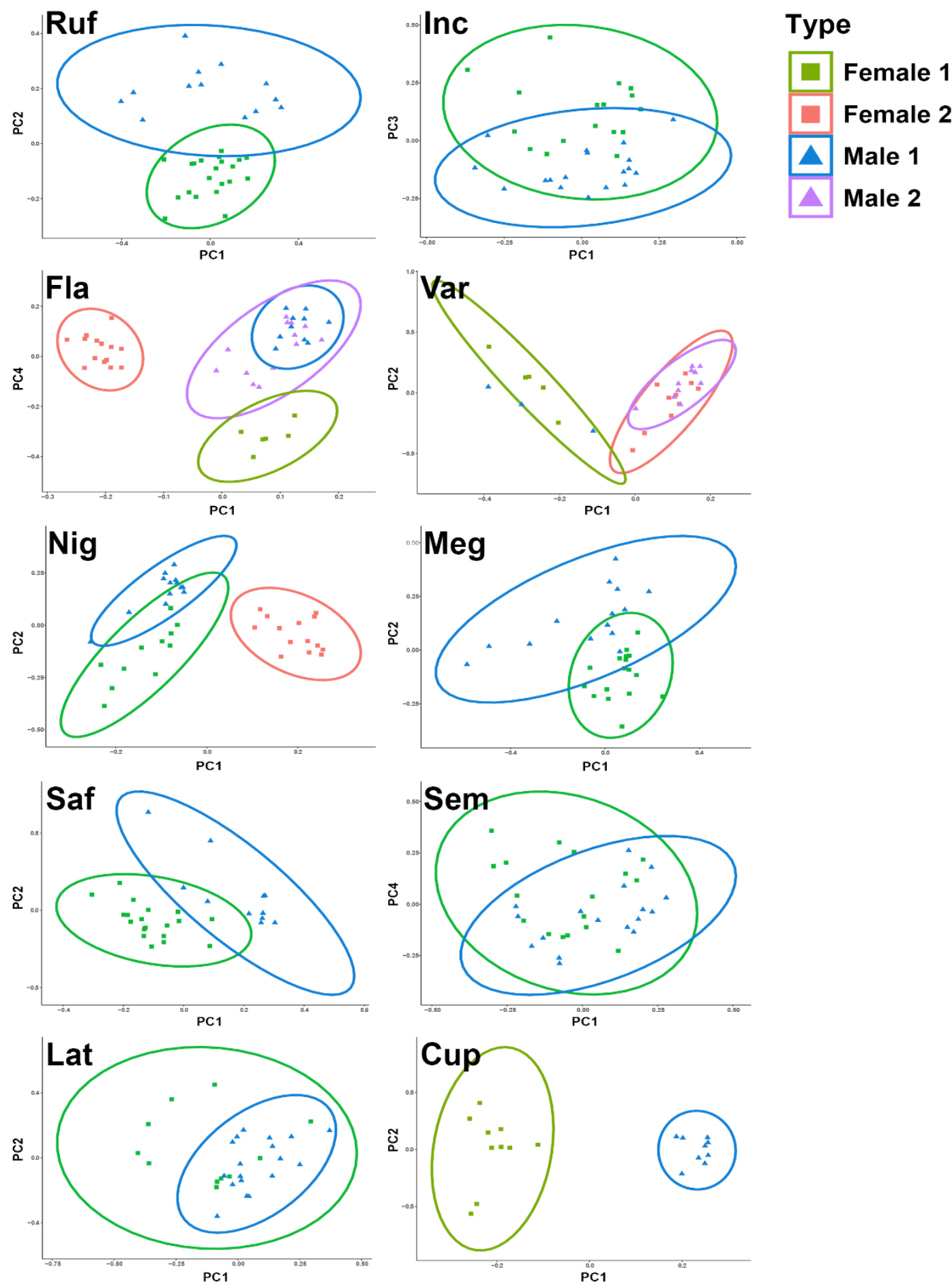
Figure 3. Intra-specific variation of CHC profiles in nine species of Australian Chrysomya and one species of Australian Lucilia. Axes represent the principal components which most significantly separated the sexes. Plots follow the same sequential order as the phylogeny (from top to bottom) and represent Ch. rufifacies, Ch. incisuralis, Ch. flavifrons, Ch. varipes, Ch. nigripes, Ch. megacephala, Ch. saffranea, Ch. semimetallica, Ch. latifrons, and L. cuprina. Ellipses were calculated based on normal multivariate distributions and represent sexes and types where present. There is no ellipse for Ch. varipes male type 1 , as only three individuals were collected.

Phylogenetic inference. A global Chrysomya phylogeny was prepared from concatenated $\mathrm{CO} 1, \mathrm{CO} 2, \mathrm{ND} 4$, and CAD. The resultant tree (Figure 4) agreed closely with previous phylogenetic trees produced by Wallman et al. (2005) and Singh et al. (2011). The genus Chrysomya is resolved as three distinct clades matching those originally designated by Singh et al. (2011). New inclusions Ch. chloropyga and Ch. inclinata resolved within the most derived clade (clade 3: Singh et al. 2011), while Ch. saffranea and Ch. phaonis resolved within clade 2 . The basal clade (clade 1) contained no newly included taxa.

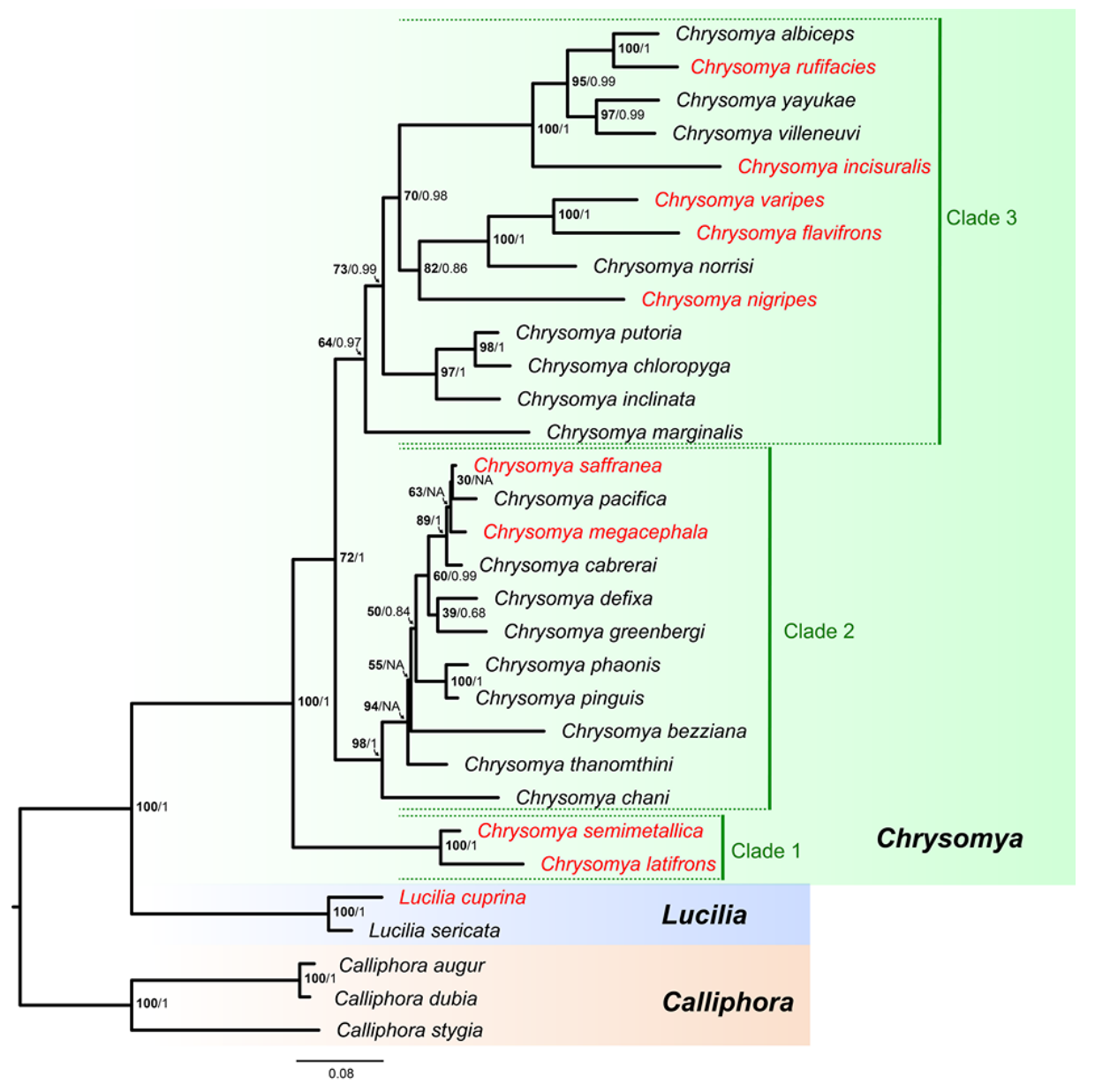

This article is protected by copyright. All rights reserved 
Figure 4: Combined molecular phylogenetic tree of global Chrysomya species in the context of the Calliphoridae. Topology represents the consensus tree from Maximum Likelihood analysis over 1000 bootstrap iterations. Node support values are shown for both Maximum Likelihood analysis (bootstrap support, 1000 iterations; in bold font) and Bayesian analysis (posterior probability, 80 million generations; regular font), 'NA' indicates nodes that were not resolved in the Bayesian analysis. Branch length scale $=0.08$ nucleotide substitutions per site. Taxa highlighted in red represent Australian species of Chrysomya and Lucilia for which cuticular hydrocarbon data were obtained.

Evolutionary change in CHCs. To visualize quantitative changes in $\mathrm{CHC}$ profiles in the context of the Chrysomya phylogeny, we traced the first three principal components from the analysis onto a pruned phylogeny which contained only the focal Australasian representatives (Figure 5). To see which peaks contributed to the mapped PCs see Supplementary Material 4: Table 6. Broadly, there appears to be have been rapid CHC diversification among Chrysomya, with the exception of Ch. rufifacies and Ch. incisuralis, as well as $C h$. megacephala and Ch. saffranea, where diversification appears more gradual. Notably, there has been substantial diversification in clade 3, particularly comparing the cuticular profiles of Ch. rufifacies and Ch. incisuralis to Ch. flavifrons, Ch. varipes, and Ch. nigripes. More so, for the latter three species, substantial divergence has also occurred in CHCs (reflected in all three PCs); however, the amount and direction of divergence differs between males and females. High levels of divergence were also observed in clade 1 between sister species $C h$. semimetallica and Ch. latifrons for male PC1 and PC2, as well as female PC1, PC2, and PC3. Notably, and in line with results from the redundancy discriminant analysis, several species shared more similar CHC profiles with distant rather than close relatives (i.e., Ch. varipes with Ch. latifrons, as well as Ch. semimetallica with Ch. megacephala, and Ch. nigripes with Ch. rufifacies and Ch. incisuralis). Except for clade 2 (Ch. megacephala and Ch. saffranea), close relatives did not tend to resemble each other more than distant relatives, suggesting that there has been limited constraint on CHC diversification in Chrysomya. 


\section{A) Male PC1}

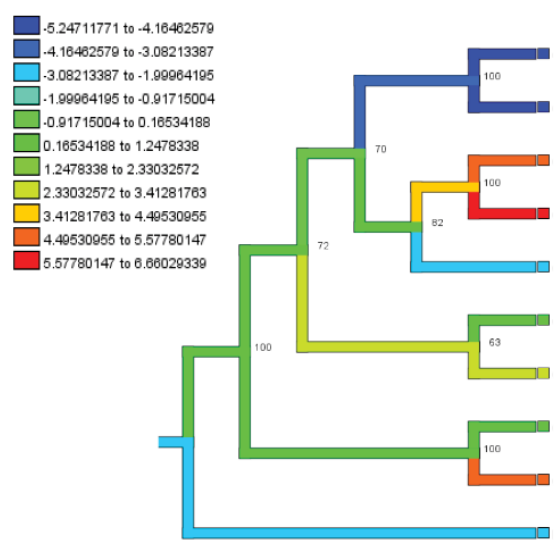

\section{B) Male PC2}

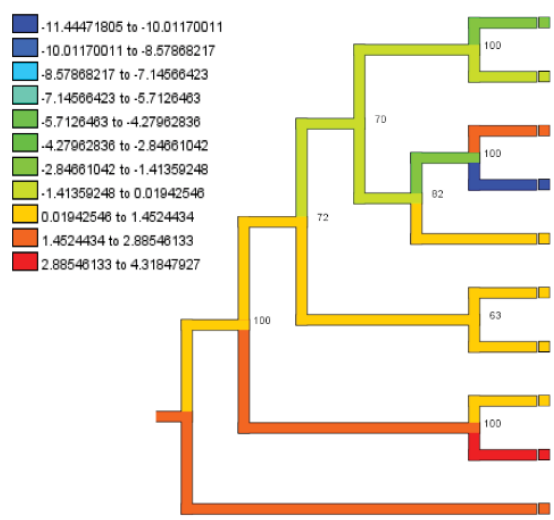

\section{C) Male PC3}

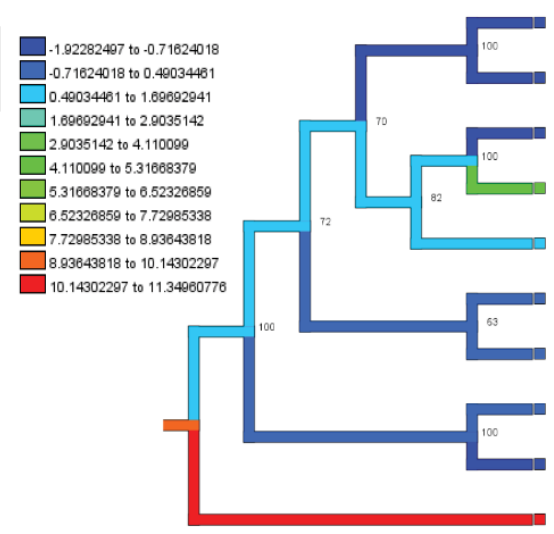

Female PC1

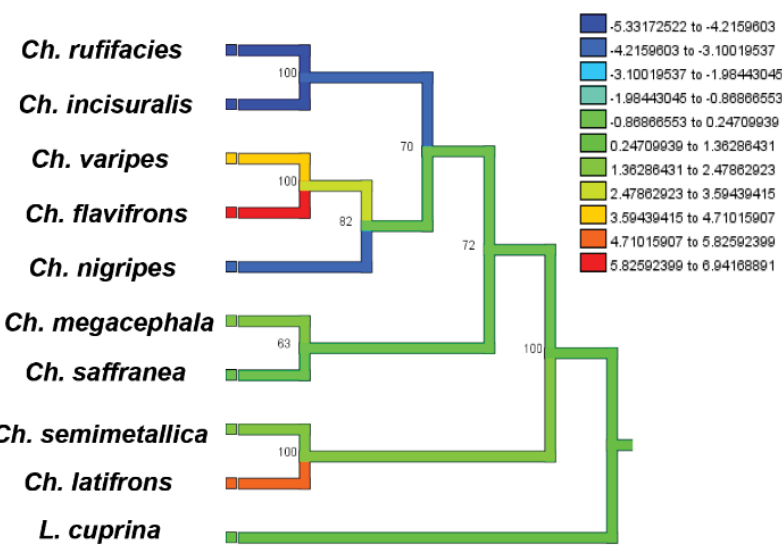

Female PC2

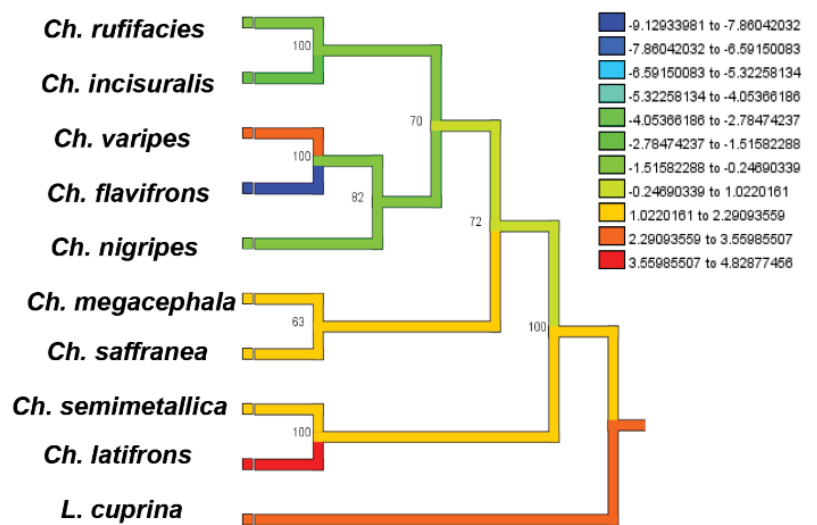

Female PC3

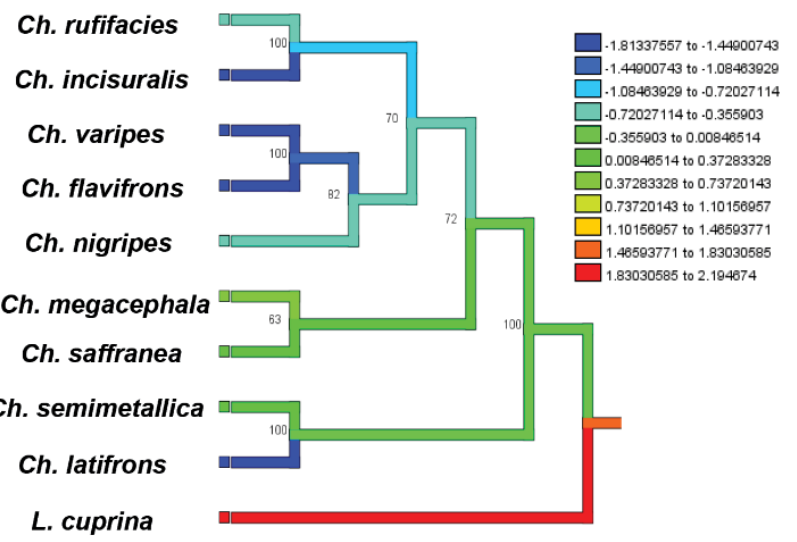


Figure 5. Figure 4.5 Character trace of male and female A) PC1, B) PC2 and C) PC3 averages (as represented by colour) onto a pruned phylogeny of Chrysomya with only Australian taxa represented. Tracing was performed using the parsimony reconstruction function of Mesquite V3.6 with the principal components representing the CHC profiles of nine species of Australian Chrysomya and Lucilia cuprina. For species with multiple profile 'types', only one was plotted. For Ch. varipes: male type 2 and female type 2, Ch. nigripes: female type 2 and Ch. flavifrons: male type 2 and female type 2."

To further elucidate these patterns of $\mathrm{CHC}$ diversification among Chrysomya, we used CoMET to assess which of nine specific evolutionary models best represents the observed character change in principal components and $\mathrm{CHC}$ proportions (Table 3). This revealed that, in males, PC1 best fit an equal model of evolution but we were unable to distinguish between punctuated and pure-phylogenetic models (AIC differences <2; Table 3a), PC2 best fit a nonphylogenetic/free model (AIC differences >2; Table 3a), and PC3 best fit a distance model but we could not distinguish between pure-phylogenetic and punctuated (AIC differences <2; Table 3a). In addition, most male CHC proportions best fit punctuated models of evolution, except for alkanes (AIC differences <2; Table 3a) and alkynes, which best fit a nonphylogenetic/free model of evolution that could not be distinguished from a purephylogenetic/distance model (AIC differences <2; Table 3a). In females, PC1 best fit a nonphylogenetic/distance model but could not be distinguished from a punctuated/equal model (AIC differences <2; Table 3b) and PC2 best fit distance models of evolution but we could not distinguish between pure-phylogenetic and non-phylogenetic (AIC differences <2; Table 3b), while PC3 best fit a pure-phylogenetic model of evolution but could not distinguish between distance and equal models (AIC differences <2; Table 3b). Similar to males, most female CHC proportions best fit punctuated/equal models of evolution, although not all could be distinguished from other models (AIC differences <2; Table 3b) with the exception of alkynes, which best fit a pure-phylogenetic model. To see which peaks contributed significantly to the mapped PCs, refer to Supplementary Material 4: Table 6. 
Table 3. CoMET results for (a) males and (b) females from Mesquite presented as AIC value differences from focal model. Asterisks represent best model; all other values are relative to the best model. Bold values represent models that were within 2 units of focal model and could therefore also be considered good fits for the data.

\begin{tabular}{|c|c|c|c|c|c|c|c|c|c|}
\hline \multirow{2}{*}{ (a) Model for trait change } & \multicolumn{3}{|c|}{ Male Profiles } & \multicolumn{6}{|c|}{ Male CHC Proportions (\%) } \\
\hline & PC1 & PC2 & PC3 & n-Alkane & Alkene & Alkadiene & Monomethylalkane & Dimethylalkane & Alkyne \\
\hline Pure-Phylogenetic/Distance & 3.66 & 10.44 & * & 3.96 & 3.9 & 1.99 & 5.7 & 7.03 & 1.54 \\
\hline Pure-Phylogenetic/Equal & 1.40 & 13.34 & 4.76 & 5.22 & 7.42 & 3.19 & 6.62 & 5.11 & 7.35 \\
\hline Pure-Phylogenetic/Free & 33.89 & 23.29 & 33.68 & 24.35 & 34.84 & 26.77 & 36.22 & 32.83 & 21.21 \\
\hline Nonphylogenetic/Distance & 2.57 & 4.81 & 5.35 & 3.76 & 6.92 & 6.85 & 4.4 & 5.28 & 11.82 \\
\hline Nonphylogenetic/Equal & 3.78 & 10.32 & 5.07 & 1.6 & 7.71 & 7.1 & 4.51 & 2.16 & 10.04 \\
\hline Nonphylogenetic/Free & 18.97 & * & 17.15 & 11.42 & 20.84 & 20.39 & 37.07 & 18.63 & * \\
\hline Punctuated/Distance & 3.27 & 7.72 & 0.18 & * & * & 0.18 & 0.68 & 2.01 & 3.06 \\
\hline Punctuated/Equal & * & 9.56 & 1.53 & 0.46 & 1.82 & * & * & * & 4.98 \\
\hline Punctuated/Free & 19.27 & 23.72 & 16.175 & 16 & 16 & 16.18 & 15.68 & 18.01 & 19.06 \\
\hline
\end{tabular}

\begin{tabular}{|c|c|c|c|c|c|c|c|c|c|}
\hline \multirow{2}{*}{ (b) Model for trait change } & \multicolumn{3}{|c|}{ Female Profiles } & \multicolumn{6}{|c|}{ Female CHC proportions (\%) } \\
\hline & PC1 & PC2 & PC3 & n-Alkane & Alkene & Alkadiene & Monomethylalkane & Dimethylalkane & Alkyne \\
\hline Pure-Phylogenetic/Distance & 2.05 & 1.25 & * & 10.26 & 8.4 & 5.71 & 16.93 & 2.26 & 0.68 \\
\hline Pure-Phylogenetic/Equal & 2.08 & 3.75 & 1.91 & 3 & 5.96 & 2.62 & 3.92 & 4.36 & * \\
\hline Pure-Phylogenetic/Free & 32.58 & 37.23 & 27.62 & 35.8 & 37.6 & 33.56 & 37.71 & 33.25 & 21.56 \\
\hline Nonphylogenetic/Distance & * & $*$ & 2.99 & 7.45 & 5.77 & 4.28 & 12.22 & 1.13 & 3.59 \\
\hline Nonphylogenetic/Equal & 4.79 & 6.74 & 3.87 & 1.75 & 4.89 & 2.72 & 1.64 & 2.42 & 2.05 \\
\hline Nonphylogenetic/Free & $2.00 \mathrm{E}+08$ & 16.72 & 26.69 & 22.84 & 21.48 & 27.22 & 10.5 & 23.63 & $2.00 E+08$ \\
\hline Punctuated/Distance & 2.32 & 3.92 & 2.49 & 6.36 & 2.37 & 3.29 & 10.69 & 0.16 & 4.77 \\
\hline Punctuated/Equal & 0.60 & 4.08 & 2.06 & $*$ & * & * & * & * & 2.69 \\
\hline Punctuated/Free & 18.32 & 19.92 & 18.49 & 22.36 & 18.37 & 19.29 & 26.69 & 16.16 & 20.77 \\
\hline
\end{tabular}

\section{DISCUSSION}

Cuticular hydrocarbons have likely played an important role in insect evolution, yet the patterns of their diversification have only been studied in a limited number of taxa. The present study aimed to document the diversification of cuticular hydrocarbons in a genus of blowflies (Chrysomya); a promising model system for evolutionary research. We quantified $\mathrm{CHCs}$ in Australian representatives of the ecologically diverse blowfly genus Chrysomya, and in support of several recent studies in other insect taxa, demonstrate that $\mathrm{CHC}$ classes are qualitatively conserved across the genus. However, for the first time, we show that quantitative $\mathrm{CHC}$ composition has evolved in a punctuated and non-phylogenetic manner in blowflies, and highlight substantial intraspecific variation related to sex and age-specific differences.

In total, we were able to identify 92 unique compounds across all 10 species; which is similar to observations in Formica ants, where 100 CHCs were identified across 13 species (Martin et al. 2008). Broadly, the monomethylalkanes, $n$-alkenes, and $n$-alkanes predominated the 
cuticular profiles of most species, which aligns with previous reports of blowfly CHCs $(L$. cuprina: Barbosa et al. 2017; Ch. varipes: Butterworth et al. 2018; Ch. rufifacies: Pechal et al. 2014; and Ch. megacephala: Paula et al. 2016). As expected, different species of Chrysomya expressed different numbers of compounds. However, while some Teleogryllus crickets express only 21 different hydrocarbons (Thomas et al. 2011), some Cyphoderris crickets only 48 hydrocarbons (Steiger et al. 2013), and Drosophila melanogaster up to 59 hydrocarbons (Everaerts et al. 2010), in Chrysomya species we saw up to 83 individual compounds expressed in individual species, suggesting that $\mathrm{CHCs}$ are particularly diverse in this genus. This diversity may be facilitated by the complex diet of blowflies; which includes a broad range of proteins and complex fatty acids from various sources including carrion, dung, and pollen (Brodie et al. 2015). As such, blowflies likely possess an arsenal of metabolic precursors for $\mathrm{CHC}$ synthesis, which may have aided the process of $\mathrm{CHC}$ diversification (Kather and Martin 2015).

Species differences. Of the $92 \mathrm{CHC}$ substances we identified, 42 were present in all species, in varying concentrations. Most notably, all C21 to C30 n-alkanes were present in every species. Such widespread qualitative conservation of $n$-alkanes in Chrysomya agrees with previous studies throughout Hymenoptera (Kather and Martin 2015) and is intuitive as alkanes are the most structurally basic CHCs and have no possible isomers. Therefore, if several species express an alkane with the same chain length, they will all express a structurally identical compound. However, for compounds such as monomethylalkanes and $n$-alkenes, for any given chain length there may be several possible isomers, and thus it is less likely for identical structures to be found across species. It is plausible that the qualitatively conserved olefinic and branched CHCs we documented may fulfil crucial roles in survival and desiccation resistance (Chung and Carroll 2015; Stinziano et al. 2015), particularly those with longer chain lengths that are expressed in relatively high proportions across all species (i.e. $2 \mathrm{MeC} 27, \mathrm{C} 27: 1, \mathrm{C} 27, \mathrm{C} 29,11 \mathrm{MeC} 27,11,13 \mathrm{MeC} 29,2 \mathrm{MeC} 31)$. However, the relationships between $\mathrm{CHC}$ class and biological function are still largely unknown (Chung and Carrol 2015; Sprenger and Menzel 2020) and is an area that requires research attention.

The other $50 \mathrm{CHC}$ substances varied substantially in both presence and concentration between closely related species. Further, each species separated distinctly based on its CHC profiles, and in several instances, closely related species shared greater similarity with distant relatives (Ch. semimetallica, Ch. varipes, and Ch. megacephala). There was also substantial intraspecific quantitative variation in $\mathrm{CHC}$ profiles, which may be the result of environmental 
variability. Nevertheless, each species clustered irrespective of geographic location, suggesting that selective pressure has led to the maintenance of species-specific $\mathrm{CHC}$ expression within Chrysomya. This holds true globally, as the CHC profiles of Australian Ch. rufifacies and Ch. megacephala are qualitatively and quantitatively similar to CHC profiles of conspecifics from other continents (Ch. rufifacies: Pechal et al. 2014; and Ch. megacephala: Paula et al. 2016). Despite this, it should be noted that we were unable to reliably distinguish the $\mathrm{CHC}$ profiles of some species. The $\mathrm{CHC}$ profiles of male $\mathrm{Ch}$. rufifacies and male Ch. incisuralis, as well as male Ch. megacephala and female $C h$. saffranea were not statistically different. However, the CHCs of females of both species were significantly different, suggesting that selection may have maintained species-specificity in female CHCs, but not male CHCs. This sex-specific diversification may be the result of differential sexual selection on $\mathrm{CHC}$ profiles. In all four species (Ch. rufifacies, Ch. incisuralis, Ch. megacephala, and Ch. saffranea) mating appears to be male-controlled (personal observation), whereby males will chase, contact, and attempt to mate with females mid-flight (Butterworth et al. 2019). This chasing behaviour would place selective pressure on males to be able to rapidly identify conspecifics during flight, a circumstance where species-specific CHCs in females may be particularly useful. This appears to be the case in tsetse flies, where males rely almost entirely on the CHC 15,19,23-trimethylheptatriacontane to identify female mates (Hall and Langley 1989). Sex-specific divergence in CHC profiles may be expected in species where mating is primarily controlled by one sex, and the benefits of correctly identifying conspecifics outweigh the cost of hybrid mating. In support of this, similar findings have been made in Nasonia wasps (Buellesbach et al. 2013) where femalespecific $\mathrm{CHC}$ divergence is a result of their use as female-specific sexual signals. Cryptic female choice should also drive divergence in the male CHC profiles, but we found no evidence for this in Ch. rufifacies, Ch. incisuralis, Ch. megacephala, or Ch. saffranea. However, we did find evidence for this in Ch. varipes and Ch. flavifrons, where we know that mating is female-controlled (Jones et al. 2014; Butterworth et al. 2019). In these species, both male and female profiles vary greatly between species - which supports the notion that both males and females may use CHCs in mate recognition and assessment in these species. Broadly, this highlights that where CHC divergence between species is considered, an accurate assessment cannot be made without considering both sexes - particularly in species which may use CHCs in sexual communication or conspecific recognition. 
Sex differences. If sexual selection has acted on the CHC profiles of Chrysomya species, we might expect to see some degree of sexual dimorphism (either in the presence or concentrations of $\mathrm{CHCs}$ ). As expected, for $80 \%$ of species, male and female profiles differed in at least one PC, the exception being Ch. varipes and Ch. semimetallica where no statistically significant differences were observed. In these two species, selection on CHCs as sex-specific cues may have been relaxed or replaced by other compounds or signalling modalities - as appears to be the case in Ch. varipes (Butterworth et al. 2018). Nevertheless, even in species where sexual dimorphisms were not clear, CHCs may still be important for conspecific recognition, as is evident in the blowfly Phormia regina (Stoffolano et al. 1997), or for the recognition of sexual maturity (Butterworth et al. in press). For the eight species that did show sexually dimorphic CHC profiles, this must either be the result of selection on sex-specific responses to environmental pressures, or sexual selection on their function in communication. The former is less likely, as although sexual dimorphisms are commonly the result of ecological selection (Taylor et al. 2019), there are no distinct differences between the environments occupied by the sexes of Chrysomya species (personal observation). Nevertheless, sex specific CHC expression in the absence of clear environmental differences has been demonstrated in Drosophila (Stinziano et al. 2015) and thus cannot be ruled out in Chrysomya. The role of environment in sexually dimorphic $\mathrm{CHC}$ expression in insects requires ongoing investigation. Despite this, it is likely that these differences are, at least in part, the result of sexual selection. Sexual selection has led to the evolution of numerous sexually dimorphic traits in blowflies, particularly within the Chrysomya. Most of these traits function in sex- and species-recognition. Prominent examples include the holoptic eyes and ocular 'bright zone' in Chrysomya megacephala males which aids in locating female's midflight (van Hateren et al. 1989), the foreleg ornamentation of male Ch. varipes (Jones et al. 2014), and the head and wing colour dimorphism of Ch. flavifrons (Butterworth et al. 2019). Given that such strong selection has occurred in this genus, it is feasible that the sexually dimorphic $\mathrm{CHC}$ profiles observed in the present study have also arisen via sexual selection, possibly for their function as sex- and species-specific mating signals. Corroborating this, there is substantial evidence for sexual selection on CHCs in L. cuprina (the species in which we observed the greatest degree of sexual dimorphism) as cuticular lipids are known to play a key role in mate recognition and male sexual attraction (Bartell 1969; Emmens, 1981). This may very well extend to Chrysomya and could be substantiated by conducting similar behavioural bioassays in species where there are obvious sexual dimorphisms. 
Notably, previous work has found $\mathrm{CHC}$ profiles to be sexually dimorphic in lab populations of Ch. varipes (Butterworth et al. 2018). However, we did not observe this in the wild populations. This is likely due to the increased environmental variation experienced by flies across natural populations, which likely drives increased variation in $\mathrm{CHC}$ profiles. Similar changes in the extent of $\mathrm{CHC}$ sexual dimorphism have been observed between lab and field populations of the hemipteran Leptoglossus occidentalis (Dapporto et al. 2013). This finding reinforces the notion that the extent of sexual dimorphism observed in a laboratory population may not be reproducible in wild populations, which raises questions about the biological significance of the initial finding. In support of this, the laboratory population of $L$. cuprina used in the present study showed comparatively minor intraspecific $\mathrm{CHC}$ variation likely due to the aforementioned effect of a standardised laboratory environment. The broader influence of environmental variation on CHC dimorphism is still unclear, so further investigation of sex-specific differences between laboratory and wild populations of blowflies would be worthwhile.

Type differences. In addition to this intra-specific $\mathrm{CHC}$ variation, we also documented substantial intra-sexual CHC variation for three species (Ch. nigripes, $C h$. varipes, and $C h$. flavifrons) in the form of multiple qualitatively distinct profile types within the same populations. These distinct types might correspond to differences in individual diet (Fedina et al. 2012) or represent intra-sexual CHC polymorphisms (Bagnères et al. 1990; Wurdack 2015; Luo et al. 2019). However, they most likely correspond with age, as it is well known that blowflies show stark age-specific changes in CHC expression (Trabalon et al. 1992; Roux et al. 2008; Pechal et al. 2014; Braga et al. 2016; Paula et al. 2016; Bernhardt et al. 2017). In fact, through laboratory rearing we have definitively confirmed age-specific changes in CHCs for Ch. varipes (Butterworth et al. in press). This being said, in wild populations of the other six Chrysomya species we were unable to identify qualitatively distinct profiles, although inspection of PCA plots does reveal some unique clusters (for example, see Ch. latifrons PCA plot; Figure 3). This may be because in the other six species, age-specific changes are more subtle, and harder to distinguish from the adult profile type, or simply that we did not collect sufficient numbers of immature individuals of these species. Importantly, the age-specific differences we observed are significant in an evolutionary context. Although it is well established that $\mathrm{CHC}$ expression is variable over insect development, particularly in blowflies, our findings highlight that assessing CHC divergence using only sexually mature adults may be misleading. For example, in the present study, 
immature $C h$. varipes (M1 and F1) showed similar $\mathrm{CHC}$ profiles to their close relative $(C h$. nigripes), whereas mature $C h$. varipes (M2 and F2) expressed vastly different profiles to $C h$. nigripes. This suggests that the pathways underlying $\mathrm{CHC}$ expression in $C h$. varipes and $C h$. nigripes are likely to be conserved, and that it is only their regulation that changes during adult development. Overall, we suggest that future studies should be cautious in drawing inferences from comparative analyses of $\mathrm{CHCs}$ without considering multiple aspects of life history (where possible), as constraints placed on one life stage may affect the $\mathrm{CHC}$ profile of other stages. While some studies have already comprehensively documented whole species CHC profiles (from egg to adult) (Roux et al. 2008; Paula et al 2016), to our knowledge none have done so in an evolutionary context. As such, to fully understand the evolution of CHCs in insects, further investigation of the adaptive function of these age-specific changes, and their wider effect on the patterns of CHC diversification will be essential.

Implications for evolution. Our observations mirror what has been found in Crematogaster ants, where the extent of phylogenetic conservation appears to be greatest when qualitative traits are considered, whereas quantitative composition diverges rapidly between species (Menzel et al. 2017b). This suggests that the biosynthetic pathways underpinning CHC synthesis in Chrysomya are conserved, but that the production and expression of individual compounds and classes are likely able to be up- or down-regulated, depending on the selective pressures acting on a given species.

To assess these trends in more detail, CoMET analysis of quantitative CHC composition (as represented by PCs and CHC proportions) was performed. This revealed that the first three PCs all fit different modes of evolution for males (PC1: punctuated/equal, PC2: nonphylogenetic/free, PC3: pure-phylogenetic/distance) as well as females (PC1 and PC2: nonphylogenetic/distance, PC3: pure-phylogenetic/distance). Although we were unable to clearly differentiate all of these models (AIC differences <2), what is apparent is that each PC differed in the model of evolution that best explained its divergence, suggesting that the compounds contributing to those PCs may have evolved under different selective pressures. This makes sense, as individual CHC substances should experience different selective pressures depending on their individual structure, physiochemical properties, and consequent biological function (Chung and Carrol 2015). Importantly, while we could not distinguish between punctuated and phylogenetic models for male PC1, the equal rate was the best fit in both cases, which is indicative of speciational change, and potentially saltational evolution (Schwander et al. 2013). Male PC2, female PC1 and female PC2 all best fit non-phylogenetic 
models - which indicates that these compounds have experienced very rapid divergence following speciation events, possibly resulting from natural or sexual selection. Lastly, male PC3 and female PC3 were best represented by pure-phylogenetic models, suggesting that there has been limited selective pressure and a slow gradual accumulation of changes in the contributing CHCs. This trend might be expected in compounds that fulfil crucial roles in survival and are widespread, or rarer compounds such as the alkynes (which contributed significantly to PC3 in both sexes and were almost exclusively found in the outgroup $L$. cuprina).

We also assessed the evolution of $\mathrm{CHC}$ proportions and found punctuated models of evolution to be the best fit in most cases. This supports the above findings, with only alkynes appearing to have evolved phylogenetically; they are rarely expressed in Chrysomya and predominantly found in male L. cuprina. For all other CHC proportions, the observed punctuated evolution may be indicative of sexual selection. Punctuated evolution suggests a correlation between speciation and saltational changes in CHCs (Schwander et al. 2013). As such, this suggests that during speciation events in Chrysomya, selective pressure may have driven saltational changes in the overall proportions of specific compound classes. Such saltational changes are often characteristic of pheromones involved in mate and species recognition, presumably due to their role in reinforcing mating isolation (van Wilgenburg 2011). This is because if CHCs facilitated sexual attraction, but changed gradually, then the likelihood of cross-attraction and hybridization would be high, hampering the process of reproductive isolation and speciation. We may only expect to observe gradual $\mathrm{CHC}$ divergence between close relatives if selective pressure on CHCs as sexual cues was relaxed. Notably, we found that punctuated models best explained the divergence of olefinic and methyl-branched CHC proportions in both sexes. It has been suggested that olefinic and branched hydrocarbons carry the most information content (due to their structural diversity) and are thus the CHCs that are most commonly adapted for sexual communication (Chung and Carroll 2015). The fact that we found the proportions of branched and olefinic compounds to change rapidly between closely related species, via punctuated evolution, may suggest that sexual selection has played a key role in their diversification. As further evidence of this, in each species the branched and olefinic hydrocarbons compounds showed the greatest differences in relative abundance between the sexes (Supplementary Material 4: Table 5). There were also sex-specific alkenes expressed in both $C h$. nigripes and $C h$. incisuralis, and sex-specific branched hydrocarbons in Ch. saffranea and L. cuprina. When 
considering candidate pheromones, it is also important to consider those peaks which explain the greatest proportion of sex-specific variation (and contribute most to PCs) (Supplementary Material 4: Table 4). This is because if certain CHCs reflect mate quality, we would predict that, according to condition-dependent selection, they should show a high degree of intrasexual variability (Delhey and Peters 2008).

Nevertheless, the punctuated diversification may also be the result of ecological adaptation. The divergence between $C h$. varipes and Ch. flavifrons supports this notion and may be the result of two main ecological considerations. First, Ch. flavifrons is a habitat specialist, restricted to the rainforests of Northern New South Wales and Queensland (Butterworth et al. 2019), whereas Ch. varipes is a habitat generalist, which is broadly distributed across the Australian continent (Butterworth et al. 2018). These extreme differences in habitat have likely led to divergent pressures on $\mathrm{CHC}$ expression for desiccation resistance, which may explain the increased proportions of $n$-alkenes and $n$-alkanes in Ch. flavifrons, in contrast to the greater proportions of monomethylalkanes in Ch. varipes. Further to this, Ch. flavifrons expresses several shorter chain hydrocarbons (C21 to C23) that are not found in Ch. varipes, which is expected in a species that inhabits wetter climates (Menzel et al. 2017a). In contrast, as a habitat generalist, Ch. varipes likely experiences much drier climates, and correspondingly the cuticle is dominated by longer chain hydrocarbons (C24 to C31). Second, as Ch. flavifrons is restricted to temperate rainforests, it has a much patchier distribution than $C h$. varipes, meaning that populations likely experience reduced gene flow (Llorens et al. 2017; De Vriendt et al. 2017), increasing the potential for changes in CHC expression to rapidly fix in a given population and subsequently increase the extent of $\mathrm{CHC}$ divergence. Similar environmental effects may also explain the rapid divergence between $C h$. semimetallica and Ch. latifrons. These sister species are largely allopatric in Australia, the former restricted primarily to warmer northern regions of Queensland and the latter restricted to temperate forests in New South Wales (Kitching 1976; Kitching and Voeten 1977). The warmer temperatures experienced by $C h$. semimetallica may have increased selection for desiccation resistance, which may explain the increased expression of C29 to C33 hydrocarbons, particularly peak 78 (DiMeC33) which constituted 2-3\% of the profile in $C h$. semimetallica but was not detected in the sister species Ch. latifrons.

Conclusion

This article is protected by copyright. All rights reserved 
CHCs have diversified rapidly in Chrysomya, are sexually dimorphic in several species, and have likely played an important role in the evolution of the genus. Importantly, we have shown for the first time that CHCs have diverged in a punctuated and non-phylogenetic manner in blowflies, possibly due to saltational changes during speciation events. It is likely that both ecological and sexual selection have shaped these patterns of CHC diversification, supporting their classification as dual traits, and our study now provides a comprehensive framework for testing such hypotheses. Future work should aim to investigate the biological function of CHCs in Chrysomya, as well as a wider variety of blowfly species, particularly focusing on the role CHCs play in environmental adaptation and sexual behaviour. Much will be gained from assessing how CHC diversification is affected by population-specific climatic conditions, as well as performing mate choice assays with reference to the candidate pheromones we have identified. More broadly, it will be crucial for future studies of CHC evolution to target multiple stages of development, consider the effect of sex on $\mathrm{CHC}$ divergence, and encompass a much wider variety of insect taxa.

\section{ACKNOWLEDGEMENTS}

This project was supported by The Holsworth Wildlife Research Endowment \& The Ecological Society of Australia. We also thank Tracey Gibson and Thomas Burley for their miscellaneous assistance, Mitchell Stares for statistical support, and Andrej Enriquez, Martin Butterworth, and Blake Dawson for their efforts with field work. The authors have no conflict of interest.

\section{DATA ACCESSIBILITY STATEMENT}

All data will be made persistently available as supplementary material upon acceptance.

\section{REFERENCES}

Alves H, Rouault J-D, Kondoh Y, Nakano Y, Yamamoto D, Kim Y-K, Jallon J-M (2010) Evolution of cuticular hydrocarbons of Hawaiian Drosophilidae. Behavior Genetics 40:694-705 doi:10.1007/s10519-010-9364-y

Arienti M, Antony C, Wicker-Thomas C, Delbecque J-P, Jallon J-M (2010) Ontogeny of Drosophila melanogaster female sex-appeal and cuticular hydrocarbons. Integrative Zoology 5:272-282 
doi:10.1111/j.1749-4877.2010.00213.x

Ashworth JR, Wall R (1995) Effects of ovarian development and protein deprivation on the activity and locomotor responses of the blowfly, Lucilia sericata, to liver odour. Physiological Entomology 20:281-285 doi:10.1111/j.1365-3032.1995.tb00816.x

Bagnères AG, Morgan ED (1990) A simple method for analysis of insect cuticular hydrocarbons Journal of Chemical Ecology 16:3263-3276 doi:10.1007/BF00982097

Barbosa RR, Braga MV, Blomquist GJ, Queiroz MMdC (2017) Cuticular hydrocarbon profiles as a chemotaxonomic tool for three blowfly species (Diptera: Calliphoridae) of forensic interest. Journal of Natural History 51:1491-1498 doi:10.1080/00222933.2017.1337944

Bartell RJ, Shorey HH, Barton Browne L (1969) Pheromonal stimulation of the sexual activity of males of the sheep blowfly Lucilia cuprina (Calliphoridae) by the female. Animal Behaviour 17:576-585 doi:10.1016/0003-3472(69)90166-3

Bartelt RJ, Armold MT, Schaner AM, Jackson LL (1986) Comparative analysis of cuticular hydrocarbons in the Drosophila virilis species group. Comparative Biochemistry and Physiology Part B: Comparative Biochemistry 83:731-742 doi:10.1016/0305-0491(86)901380

Bernhardt V, Pogoda W, Verhoff MA, Toennes SW, Amendt J (2017) Estimating the age of the adult stages of the blow flies Lucilia sericata and Calliphora vicina (Diptera: Calliphoridae) by means of the cuticular hydrocarbon n-pentacosane. Science \& Justice 57:361-365 doi:10.1016/j.scijus.2017.04.007

Brodie BS, Babcock T, Gries R, Benn A, Gries G (2015) Acquired smell? Mature females of the common green bottle fly shift semiochemical preferences from feces feeding sites to carrion oviposition sites. Journal of Chemical Ecology 42:40-50 doi:10.1007/s10886-015-0658-7

Buellesbach J, Gadau J, Beukeboom LW, Echinger F, Raychoudhury R, Werren JH, Schmitt T (2013) Cuticular hydrocarbon divergence in the jewel wasp Nasonia: evolutionary shifts in chemical communication channels? Journal of Evolutionary Biology 26:2467-2478 doi:10.1111/jeb.12242

Buellesbach J, Vetter SG, Schmitt T (2018) Differences in the reliance on cuticular hydrocarbons as sexual signaling and species discrimination cues in parasitoid wasps. Frontiers in Zoology 15:22 doi:10.1186/s12983-018-0263-z

Butterworth NJ, Byrne PG, Keller PA, Wallman JF (2018) Body odor and sex: Do cuticular hydrocarbons facilitate sexual attraction in the small hairy maggot blowfly? Journal of Chemical Ecology 44:248-256 doi:10.1007/s10886-018-0943-3

Butterworth NJ, Byrne PG, Wallman JF (2019) The blow fly waltz: Field and laboratory observations of novel and complex dipteran courtship behavior. Journal of Insect Behavior 32:109-119 doi:10.1007/s10905-019-09720-1

Butterworth NJ, Drijfhout FP, Byrne PG, Keller PA, Wallman JF (in press) Major transitions in

This article is protected by copyright. All rights reserved 
cuticular hydrocarbon expression coincide with sexual maturity in a blowfly (Diptera: Calliphoridae). Journal of Chemical Ecology 10.1007/s10886-020-01194-2

Caputo B et al. (2005) Identification and composition of cuticular hydrocarbons of the major Afrotropical malaria vector Anopheles gambiae s.s. (Diptera: Culicidae): analysis of sexual dimorphism and age-related changes. Journal of Mass Spectrometry 40:1595-1604 doi:10.1002/jms.961

Chung H, Carroll SB (2015) Wax, sex and the origin of species: Dual roles of insect cuticular hydrocarbons in adaptation and mating. BioEssays 37:822-830 doi:10.1002/bies.201500014

Curran J (2018) Hotelling: Hotelling's T^2 Test and Variants R Package Version 1.0-5 https://cran.rproject.org/package=Hotelling

Curtis S, Sztepanacz JL, White BE, Dyer KA, Rundle HD, Mayer P (2013) Epicuticular compounds of Drosophila subquinaria and D. recens: Identification, quantification, and their role in female mate choice. Journal of Chemical Ecology 39:579-590 doi:10.1007/s10886-013-02841

Dapporto L, Baracchi D, Benassai D, Capretti P, Roversi PF, Turillazzi S (2013) Major changes in the sex differences in cuticular chemical profiles of the western conifer seed bug (Leptoglossus occidentalis) after laboratory rearing. Journal of Insect Physiology 59:738-744 doi:10.1016/j.jinsphys.2013.03.012

De Vriendt L et al. (2016) Population isolation shapes plant genetics, phenotype and germination in naturally patchy ecosystems. Journal of Plant Ecology 10:649-659 doi:10.1093/jpe/rtw071

Delhey K, Peters A (2008) Quantifying variability of avian colours: are signalling traits more variable? PloS One 3:e1689-e1689 doi:10.1371/journal.pone.0001689

Dray S, Dufour A (2007) The ade4 Package: Implementing the duality diagram for ecologists. Journal of Statistical Software 22:1-20 doi: 10.18637/jss.v022.io4

Edgar RC (2004) MUSCLE: multiple sequence alignment with high accuracy and high throughput. Nucleic Acids Research 32, 1792-1797 doi:10.1093/nar/gkh340

Emmens RL (1981) Evidence for an attractant in cuticular lipids of female Lucilia cuprina (Wied.), Australian sheep blowfly. Journal of Chemical Ecology 7:529-541 doi:10.1007/BF00987701

Everaerts C, Farine J, Cobb M, Ferveur J (2010) Drosophila cuticular hydrocarbons revisited: Mating status alters cuticular profiles. PLoS ONE 5:e9607 doi:10.1371/journal.pone.0009607

Fedina TY, Kuo T-H, Dreisewerd K, Dierick HA, Yew JY, Pletcher SD (2012) Dietary effects on cuticular hydrocarbons and sexual attractiveness in Drosophila. PLoS One 7:e49799 doi:10.1371/journal.pone.0049799

Ferrar P (1987) A guide to the breeding habits and immature stages of Diptera Cyclorrhapha. Brill Leiden, The Netherlands

Ferveur J (2005) Cuticular hydrocarbons: Their evolution and roles in Drosophila pheromonal communication. Behavior Genetics 35:279-295 doi:10.1007/s10519-005-3220-5

This article is protected by copyright. All rights reserved 
Goodrich BS (1970) Cuticular lipids of adults and puparia of the Australian sheep blowfly Lucilia cuprina (Wied.) Journal of Lipid Research 11:1-6

Hall MJR, Langley PA (1989) The responses of individual males in an isolated population of Glossina morsitans (Diptera: Glossinidae) to pheromone-baited decoy 'females'. Bulletin of Entomological Research 79:319-334 Hervé MR, Nicolè F, Lê Cao K-A (2018) Multivariate analysis of multiple datasets: A practical guide for chemical ecology. Journal of Chemical Ecology 44:215-234 doi:10.1007/s10886-018-0932-6

Hervé MR (2020) RVAideMemoire: Testing and plotting procedures for biostatistics. R package version 0.9-74. https://cran.r-project.org/package=RVAideMemoire

Hughes GP, Bello JE, Millar JG, Ginzel MD (2015) Determination of the absolute configuration of female-produced contact sex pheromone components of the longhorned beetle, Neoclytus acuminatus acuminatus (F). Journal of Chemical Ecology 41:1050-1057 doi:10.1007/s10886015-0639-х

Ingleby F (2015) Insect cuticular hydrocarbons as dynamic traits in sexual communication. Insects 6:732-742 doi:10.3390/insects6030732

Jallon J, David JR (1987) Variations in cuticular hydrocarbons among the eight species of the Drosophila melanogaster subgroup. Evolution 41:294-302 doi:10.1111/j.15585646.1987.tb05798.x

Jolliffe I (2002) Principal component analysis. Springer, New York

Jones SD, Byrne PG, Wallman JF (2014) Mating success is predicted by the interplay between multiple male and female traits in the small hairy maggot blowfly. Animal Behaviour 97:193200 doi:10.1016/j.anbehav.2014.09.022

Kassambra A, Mundt F (2017) factoextra: Extract and visualize the results of multivariate data analyses. R Package Version 1.0.4. https://CRAN.R project.org/package=factoextra

Kather R, Martin S (2015) Evolution of cuticular hydrocarbons in the Hymenoptera: A meta-analysis. Journal of Chemical Ecology 41:871-883 doi:10.1007/s10886-015-0631-5

Kitching R (1976) The immature stages of the Old-World screw-worm fly, Chrysomya bezziana Villeneuve, with comparative notes on other Australasian species of Chrysomya (Diptera, Calliphoridae). Bulletin of entomological research 66:195-203 doi:10.1017/S0007485300006635

Kitching R, Voeten R (1977) The larvae of Chrysomya incisuralis (Macquart) and Ch. (Eucompsomyia) semimetallica (Malloch) (Diptera: Calliphoridae). Australian Journal of Entomology 16:185-190 doi:10.1111/j.1440-6055.1977.tb00083.x

Kuo T-H, Yew JY, Fedina TY, Dreisewerd K, Dierick HA, Pletcher SD (2012) Aging modulates cuticular hydrocarbons and sexual attractiveness in Drosophila melanogaster. The Journal of Experimental Biology 215:814-821 doi: 10.1242/jeb.064980

Kutty Sujatha N, Pape T, Wiegmann Brian M, Meier R (2010) Molecular phylogeny of the

This article is protected by copyright. All rights reserved 
Calyptratae (Diptera: Cyclorrhapha) with an emphasis on the superfamily Oestroidea and the position of Mystacinobiidae and McAlpine's fly. Systematic Entomology 35:614-635 doi:10.1111/j.1365-3113.2010.00536.x

Kutty SN, Meusemann K, Bayless KM, Marinho MAT, Pont AC, Zhou X, Misof B, Wiegmann BM, Yeates D, Ceretti P, Meier R, Pape T (2019) Phylogenomic analysis of Calyptratae: Resolving the phylogenetic relationships within a major radiation of Diptera. Cladistics 35:605-622 doi:10.1111/cla.12375

Lanfear, R., Frandsen, P.B., Wright, A.M., Senfeld, T. \& Calcott, B. (2017) Partitionfinder 2: New methods for selecting partitioned models of evolution for molecular and morphological phylogenetic analyses. Molecular Biology and Evolution 34:772-773. doi:10.1093/molbev/msw260

Lee C, Blay S, Mooers AØ, Singh A, Oakley TH (2006) CoMET: A mesquite package for comparing models of continuous character evolution on phylogenies. Evolutionary Bioinformatics 2:183186 doi: $10.1177 / 117693430600200022$

Legendre P, Legendre, L.F. (2012) Numerical Ecology Elsevier Amsterdam, The Netherlands

Llorens TM, Tapper S-L, Coates DJ, McArthur S, Hankinson M, Byrne M (2017) Does population distribution matter? Influence of a patchy versus continuous distribution on genetic patterns in a wind-pollinated shrub. Journal of Biogeography 44:361-374 doi:10.1111/jbi.12843

Luo Y, Zhang Y, Farine J-P, Ferveur J-F, Ramírez S, Kopp A (2019) Evolution of sexually dimorphic pheromone profiles coincides with increased number of male-specific chemosensory organs in Drosophila prolongate. Ecology and Evolution 9:13608-13618 doi:10.1002/ece3.5819

Maddison WP, Maddison DR (2019) Mesquite: a modular system for evolutionary analysis. Version $3.6 \mathrm{http}: / / \mathrm{www} . \mathrm{mesquiteproject.org}$

Marinho MAT, Junqueira ACM, Paulo DF, Esposito MC, Villet MH, Azeredo-Espin AML (2012) Molecular phylogenetics of Oestroidea (Diptera: Calyptratae) with emphasis on Calliphoridae: Insights into the inter-familial relationships and additional evidence for paraphyly among blowflies. Molecular Phylogenetics and Evolution 65:840-854 doi: 10.1016/j.ympev.2012.08.007

Martin SJ, HelanterÄ H, Drijfhout FP (2008) Evolution of species-specific cuticular hydrocarbon patterns in Formica ants. Biological Journal of the Linnean Society 95:131-140 doi:10.1111/j.1095-8312.2008.01038.x

Menzel F, Blaimer BB, Schmitt T (2017a) How do cuticular hydrocarbons evolve? Physiological constraints and climatic and biotic selection pressures act on a complex functional trait. Proceedings of the Royal Society B 284:1850 https://doi.org/10.1098/rspb.2016.1727

Menzel F, Schmitt T, Blaimer BB (2017b) The evolution of a complex trait: cuticular hydrocarbons in ants evolve independent from phylogenetic constraints. Journal of Evolutionary Biology 30:1372-1385 doi:10.1111/jeb.13115

This article is protected by copyright. All rights reserved 
Miller JK, Farr SD (1971) Bimultivariate redundancy: A comprehensive measure of interbattery relationship. Multivariate Behavioral Research 6:313-324 doi:10.1207/s15327906mbr0603_4

Miller, M.A., Pfeiffer, W. \& Schwartz, T. (2010) Creating the CIPRES science gateway for inference of large phylogenetic trees. 2010 Gateway Computing Environments Workshop (GCE) doi:10.1109/GCE.2010.5676129

Mullen SP, Mendelson TC, Schal C, Shaw KL (2007) Rapid evolution of cuticular hydrocarbons in a species radiation of acoustically diverse Hawaiian crickets (Gryllidae: Trigonidiinae: Laupala). Evolution 61:223-231 doi:10.1111/j.1558-5646.2007.00019.x

Nelson, L.A., Lambkin, C.L., Batterham, P., Wallman, J.F., Dowton, M., Whiting, M.F., Yeates, D.K. \& Cameron, S.L. (2012) Beyond barcoding: A mitochondrial genomics approach to molecular phylogenetics and diagnostics of blowflies (Diptera: Calliphoridae). Gene 511, 131-142. doi:10.1016/j.gene.2012.09.103

Nelson, L.A., Wallman, J.F. \& Dowton, M. (2007) Using COI barcodes to identify forensically and medically important blowflies. Medical and Veterinary Entomology 21:44-52 doi:10.1111/j.1365-2915.2007.00664.x

Nelson, L.A., Wallman, J.F. \& Dowton, M. (2008) Identification of forensically important Chrysomya (Diptera: Calliphoridae) species using the second ribosomal internal transcribed spacer (ITS2). Forensic Science International 177:238-247 doi:10.1016/j.forsciint.2008.01.009

Niogret J, Felix A-E, Nicot A, Lumaret J-P (2019) Chemosystematics using cuticular compounds: A powerful tool to separate species in Mediterranean dung beetles (Coleoptera: Geotrupidae). Journal of Insect Science 19:18 doi:10.1093/jisesa/iez026

Norris KR (1959) The ecology of sheep blowflies in Australia. Biogeography and Ecology in Australia. Springer Netherlands, Dordrecht, pp 514-544. doi:10.1007/978-94-017-6295-3_32

Oksanen J, Blanchet G, Friendly M, Kindt R, Legendre P, McGlinn D, Minchin PR, O'Hara RB, Simpson GL, Solymos P, Stevens MHH, Szoecs E and Wagner H (2019) vegan: Community ecology package. $\mathrm{R}$ package version 2.5-5. https://CRAN.R-project.org/package=vegan

Oliveira CC, Manfrin MH, Sene MF, Jackson LL, Etges WJ (2011) Variations on a theme: diversification of cuticular hydrocarbons in a clade of cactophilic Drosophila. BMC Evolutionary Biology 11:179 doi:10.1186/1471-2148-11-179

Ottensmann M, Stoffel MA, Nichols HJ, Hoffman JI (2018) GCalignR: An R package for aligning gas-chromatography data for ecological and evolutionary studies. PLoS One 13:e0198311 doi:10.1371/journal.pone.0198311

Paula MC et al. (2016) Chemotaxonomic profile and intraspecific variation in the blow fly of forensic interest Chrysomya megacephala (Diptera: Calliphoridae). Journal of Medical Entomology 54:14-23 doi:10.1093/jme/tjw142

Pechal JL, Moore H, Drijfhout F, Benbow ME (2014) Hydrocarbon profiles throughout adult Calliphoridae aging: A promising tool for forensic entomology Forensic Science 
International 245:65-71 doi:10.1016/j.forsciint.2014.10.019

Peres-Neto PR, Legendre P, Dray S, Borcard D (2006) Variation partitioning of species data matrices: Estimation and comparison of fractions. Ecology 87:2614-2625 doi:10.1890/00129658(2006)87[2614:VPOSDM]2.0.CO;2

Quinn GP, Keough MJ (2002) Experimental design and data analysis for biologists. Cambridge University Press Cambridge, United Kingdom

R Core Team (2019). R: A language and environment for statistical computing. R Foundation for Statistical Computing, Vienna, Austria. URL https://www.R-project.org/.

Roux O, Gers C, Legal L (2008) Ontogenetic study of three Calliphoridae of forensic importance through cuticular hydrocarbon analysis. Medical and Veterinary Entomology 22:309-317 doi:10.1111/j.1365-2915.2008.00752.x

Schwander T, Arbuthnott D, Gries R, Gries G, Nosil P, Crespi BJ (2013) Hydrocarbon divergence and reproductive isolation in Timema stick insects. BMC Evolutionary Biology 13:151 doi:10.1186/1471-2148-13-151

Servedio MR, Doorn GSV, Kopp M, Frame AM, Nosil P (2011) Magic traits in speciation: 'magic' but not rare? Trends in Ecology \& Evolution 26:389-397 doi:10.1016/j.tree.2011.04.005

Singh B, Kurahashi H, Wells JD (2011) Molecular phylogeny of the blowfly genus Chrysomya. Medical And Veterinary Entomology 25:126-134 doi:10.1111/j.1365-2915.2010.00914.x

Smadja C, Butlin RK (2009) On the scent of speciation: the chemosensory system and its role in premating isolation. Heredity 102:77-97 doi:10.1038/hdy.2008.55

Sprenger PP, Burkert LH, Abou B, Federle W, Menzel F (2018) Coping with the climate: cuticular hydrocarbon acclimation of ants under constant and fluctuating conditions. The Journal of Experimental Biology 221:jeb171488 doi:10.1242/jeb.171488

Sprenger PP, Menzel F (2020) Cuticular hydrocarbons in ants (Hymenoptera: Formicidae) and other insects: how and why they differ among individuals, colonies, and species. Myrmecological News 30:1-26 doi:10.25849/myrmecol.news.030:013

Stamatakis, A. (2014) RAxML version 8: A tool for phylogenetic analysis and post-analysis of large phylogenies. Bioinformatics 30, 1312-1313. doi:10.1093/bioinformatics/btu033

Steiger S, Ower GD, Stökl J, Mitchell C, Hunt J, Sakaluk SK (2013) Sexual selection on cuticular hydrocarbons of male sagebrush crickets in the wild. Proceedings of the Royal Society of London B 280 doi:10.1098/rspb.2013.2353

Stinziano JR, Sové RJ, Rundle HD, Sinclair BJ (2015) Rapid desiccation hardening changes the cuticular hydrocarbon profile of Drosophila melanogaster. Comparative Biochemistry and Physiology Part A: Molecular \& Integrative Physiology 180:38-42 doi:10.1016/j.cbpa.2014.11.004

Stoffolano JG, Schauber E, Yin C-M, Tillman JA, Blomquist GJ (1997) Cuticular hydrocarbons and their role in copulatory behavior in Phormia regina (Meigen). Journal of Insect Physiology

This article is protected by copyright. All rights reserved 
43:1065-1076 doi:10.1016/S0022-1910(97)00050-4

Symonds MRE, Moussalli A, Elgar MA (2009) The evolution of sex pheromones in an ecologically diverse genus of flies. Biological Journal of the Linnean Society 97:594-603 doi:10.1111/j.1095-8312.2009.01245.x

Symonds MRE, Wertheim B (2005) The mode of evolution of aggregation pheromones in Drosophila species. Journal of Evolutionary Biology 18:1253-1263 doi:10.1111/j.14209101.2005.00971.x

Tang Y, Horikoshi M, Li W (2016) ggfortify: Unified Interface to Visualize Statistical Result of Popular R Packages. The R Journal 8 https://journal.r-project.org/.

Taylor LA, Cook C, McGraw KJ (2019) Variation in activity rates may explain sex-specific dorsal color patterns in Habronattus jumping spiders. PLoS One 14:e0223015 doi:10.1371/journal.pone.0223015

Thomas ML, Gray B, Simmons LW (2011) Male crickets alter the relative expression of cuticular hydrocarbons when exposed to different acoustic environments. Animal Behaviour 82:49-53 doi:10.1016/j.anbehav.2011.03.023

Toolson EC, Markow TA, Jackson LL, Howard RW (1990) Epicuticular hydrocarbon composition of wild and laboratory-reared Drosophila mojavensis Patterson and Crow (Diptera: Drosophilidae). Annals of the Entomological Society of America 83:1165-1176 doi:10.1093/aesa/83.6.1165

Trabalon M, Campan M, Clement J-L, Lange C, Miquel M-T (1992) Cuticular hydrocarbons of Calliphora vomitoria (Diptera): Relation to age and sex. General and Comparative Endocrinology 85:208-216 doi:10.1016/0016-6480(92)90004-4

Van Hateren J, Hardie R, Rudolph A, Laughlin S, Stavenga D (1989) The bright zone, a specialized dorsal eye region in the male blowfly Chrysomyia megacephala. Journal of Comparative Physiology A 164:297-308 doi:10.1007/BF00612990

Van Oystaeyen A, Oliveira RC, Holman L, van Zweden JS, Romero C, Oi CA, d'Ettore P, Khalesi M, Billen J, Wäckers F, Millar JG, Wenseleers T (2014) Conserved class of queen pheromones stops social insect workers from reproducing. Science 343:287-290 doi: 10.1126/science. 1244899

van Wilgenburg E, Symonds MRE, Elgar MA (2011) Evolution of cuticular hydrocarbon diversity in ants. Journal of Evolutionary Biology 24:1188-1198 doi:10.1111/j.1420-9101.2011.02248.x

Wallman, J.F., Leys, R. \& Hogendoorn, K. (2005) Molecular systematics of Australian carrionbreeding blowflies (Diptera: Calliphoridae) based on mitochondrial DNA. Invertebrate Systematics 19: 1-15 doi:10.1071/IS04023

Wells JD, Kurahashi H (1996) A new species of Chrysomya (Diptera:Calliphoridae) from Sulawesi, Indonesia, with a key to the Oriental, Australasian and Oceanian species. Medical Entomology and Zoology 47:131-138 doi:10.7601/mez.47.131

This article is protected by copyright. All rights reserved 
Wells, J.D., Pape, T. \& Sperling, F.A.H. (2001) DNA-based identification and molecular systematics of forensically important Sarcophagidae (Diptera). Journal of Forensic Sciences 46, 10981102. doi:10.1007/s00414-009-0395-y

Wurdack M et al. (2015) Striking cuticular hydrocarbon dimorphism in the mason wasp Odynerus spinipes and its possible evolutionary cause (Hymenoptera: Chrysididae, Vespidae). Proceedings of the Royal Society B 282:20151777 doi:10.1098/rspb.2015.1777

This article is protected by copyright. All rights reserved 